\title{
UN LUSTRO DE CONSOLIDACIÓN NORMATIVA EN MATERIA DE ESTABILIDAD PRESUPUESTARIA EN ESPAÑA. ANÁLISIS CRÍTICO, BALANCE Y PERSPECTIVAS DE FUTURO
}

\author{
Luis Carlos Femia Julve \\ Doctorando en Derecho Financiero y Tributario \\ Facultad de Derecho. Universidad Complutense de Madrid \\ LuisCarlosFemia@gmail.com
}

\begin{abstract}
RESUMEN
En este trabajo se lleva a cabo, en primer término, un análisis crítico de la configuración normativa en materia de estabilidad presupuestaria en nuestro país durante los últimos cinco años como resultado de la influencia del Derecho comunitario. Después se evalúa el impacto y efectos de dicha normativa. Finalmente se plantean algunas propuestas o consideraciones profuturo.

Palabras clave: estabilidad presupuestaria, sostenibilidad, déficit público, deuda pública, gasto público, cuentas públicas, Comunidad Autónoma, Estado, gobierno.
\end{abstract}

\section{ABSTRACT}

In this piece of work we analyze, first of all, the regulation body regarding the budget stability in Spain for the past five years, as a result of the influence of the Community Law. Following the analysis we assess the impact and effects of such laws. Last but not least we offer several suggestions and considerations for the future.

Keywords: Budget stability, sustainability, public deficit, public debt, public expense, public account, Autonomous Region, State, government.

\section{ZUSAMMENFASSUNG}

Diese Arbeit führt in erster Linie eine kritische Analyse der normativen Gestaltung in Bezug auf die Stabilisierung des Staatshaushalts wäbrend der letzten 5 Jahre unter dem Einfluss des EU-Rechts durch. Anschließend werden die Wirkung und die Auswirkungen dieses Gesetzes bewertet. Abschließend werden einige Vorschläge und Erwägungen zur Zukunft geäußert.

Schlüsselwörter: Stabilität des Staatshaushalts, Nachhaltigkeit, Staatsschulden, öffentliche Schulden, Staatsausgaben, Staatshaushalt, Autonome Gemeinschaft, Staat, Regierung. 
SUMARIO: I. INTRODUCCIÓN.-II. GÉNESIS DE LA CUESTIÓN, INTERVENCIONISMO COMUNITARIO Y SEGUIDISMO ESTATAL.-III. CONFIGURACIÓN NORMATIVA DE LA ESTABILIDAD PRESUPUESTARIA EN NUESTRO PAÍS.-1. La reforma constitucional de agosto de 2011: el renombrado art. 135.-2. El desarrollo normativo y la problemática estructura del Estado plurilegislativo «indefinido».-A) Cuestiones preliminares: a vueltas con el modelo territorial.-B) Legislación estatal y autonómica.-a) Objeto, criterios de aplicación y principios rectores. - b) Reglas fiscales. - c) Instrumentación de las reglas fiscales.—d) Medidas preventivas, correctivas y coercitivas. e) Otras cuestiones complementarias.-IV. BALANCE.-V. PERSPECTIVAS DE FUTURO.-VI. BIBLIOGRAFÍA.

\section{INTRODUCCIÓN}

Han transcurrido casi cinco años desde aquel famoso miércoles 12 de mayo de 2010, fecha en la que el entonces presidente del gobierno, José Luis Rodríguez Zapatero, comparece ante el Pleno del Congreso de los Diputados para anunciar la adopción de una serie de medidas adicionales ${ }^{1}$ destinadas a acelerar la reducción del gasto público — medidas, dicho sea de paso, excesivamente ambiciosas y utópicas, dado que, sumadas a las ya implementadas, pretendían reducir en tan sólo dos años el déficit del 11 al 6 por 100 del PIB-.

Aquí encontramos el origen de un nuevo paradigma normativo. Las políticas anticíclicas y expansivas promulgadas para combatir los embates de la crisis iniciada en octubre de 2008 comienzan a dar paso a otras de corte procíclico y contractivo que, imbuidas por un marcado e indudable sesgo ideológico, reactivan y aceleran el proceso de consolidación fiscal iniciado durante los años noventa del siglo pasado.

${ }^{1}$ El proceso de consolidación interno se inicia con la aprobación de la Ley 26/2009, de 23 de diciembre, de Presupuestos Generales para el año 2010, que eleva determinados impuestos y reduce los gastos corrientes de forma significativa. En la misma senda, el 29 de enero de 2010, el Consejo de Ministros aprueba dos planes de recorte del gasto público en el ámbito de la Administración General del Estado (Plan de Acción Inmediata 2010 y Plan de Austeridad 2011-2013) y propone dos Acuerdos Marco con Comunidades Autónomas (CCAA) y Corporaciones Locales (CL), comprometiendo a todos los niveles de la Administración Pública en el empeño de reducción del gasto. 


\section{GÉNESIS DE LA CUESTIÓN, INTERVENCIONISMO COMUNITARIO Y SEGUIDISMO ESTATAL}

No estamos, ni mucho menos, ante un principio jurídico de reciente creación ${ }^{2}$. Sí resulta novedoso, en cambio, el tratamiento normativo que se le viene otorgando al mismo durante los últimos años. Frente a su tradicional configuración como postulado propio del Derecho presupuestario, en tanto en cuanto su utilidad se reconducía a las diferentes fases de este instituto, y tras un periodo de regulación legal de diez años iniciado con la aprobación de la Ley 18/2001, de 12 de diciembre, General de Estabilidad Presupuestaria, y la Ley Orgánica 5/2001, de 13 de diciembre, complementaria de la anterior ${ }^{3}$, desde la reforma constitucional de 2011 nos encontramos ante un verdadero axioma orientador y referencial de nuestro ordenamiento jurídico.

Para analizar este cambio de enfoque, la referencia al Derecho europeo —aunque sinóptica - resulta obligada, pues es en este ámbito supranacional en el que, con ciertos matices ${ }^{4}$, surge y se desarrolla la estabilidad presupuestaria hasta alcanzar su composición presente.

${ }^{2}$ Parte de la doctrina ha identificado el art. 340 de la Constitución de 1812 como la formulación primigenia del principio de equilibrio de las cuentas públicas. Véase A. CAYÓN GALIARDO, «El principio de equilibrio presupuestario como límite al poder financiero de las Cortes Generales», en VVAA, Funciones financieras de las Cortes Generales, Madrid, Congreso de los Diputados (1985), p. 97, o M. Garcés SANAGUSTín, «En torno al concepto de estabilidad presupuestaria en España», en VVAA, La estabilidad presupuestaria en el Derecho español, Madrid, Instituto de Estudios Fiscales (2004), p. 26, quien además sostiene que «el antecedente inmediato y único del mismo radica en el principio de equilibrio presupuestario, incorporado al espacio jurídico desde la doctrina económica y política». Otros, en cambio, han considerado que lo único que se ponía de manifiesto en estas normas era un equilibrio formal o contable amparado en la idea de que el gasto público debía financiarse mediante los tributos y las rentas procedentes del patrimonio público, impidiéndose, por tanto, la posibilidad de equilibrarlo formalmente recurriéndose a la deuda. Véase J. GARCía Roca y M. Á. MartíneZ LAGo, Estabilidad presupuestaria y consagración del freno al endeudamiento, Madrid, Aranzadi Thomson Reuters-Instituto de Derecho Parlamentario de la Universidad Complutense de Madrid (2013), pp. 61-62.

${ }^{3}$ Huelga recordar que las directrices trazadas en el Consejo Europeo de Santa María de Feira, celebrado los días 19 y 20 de junio de 2000, que urgían a los Estados miembros a avanzar en el saneamiento de sus cuentas más allá de lo estipulado en el Pacto de Estabilidad y Crecimiento aprobado en 1997, fueron decisivas para la concreción de leyes de este tipo en nuestro Derecho interno.

${ }^{4}$ Véase E. Denia Cosimo, «En busca de la soberanía perdida. El principio de equilibrio presupuestario entre la coordinación constitucional y la reforma de la gobernanza económica de la Unión Europea», en VVAA, La constitucionalización de la estabilidad presupuestaria, Madrid, Instituto de Derecho Público-Universidad Rey Juan Carlos (2012), pp. 86, 91 y 95. 
El fracaso prematuro del modelo de coordinación de las políticas económicas nacionales recogido en el Tratado de Funcionamiento de la Unión Europea (TFUE), en vigor desde el 1 de enero de 2009, unido al aumento deliberado del gasto por parte de los Estados miembros para compensar la caída de la actividad productiva, pone de relieve la necesidad de articular un nuevo diseño más eficiente fundamentado en premisas radicalmente opuestas a las anteriores. Frente al sistema primario, caracterizado por la preponderancia de los Estados y la ausencia de mecanismos que posibilitaran encauzar y sancionar las políticas domésticas contrarias a las orientaciones comunitarias ${ }^{5}$, se gesta un nuevo modelo de gobernanza económica reforzado en el que los ejecutivos de los diferentes países de la Unión pasan a ocupar una posición subordinada y el Consejo Europeo adquiere una posición central y cuasihegemónica —upstream competencial— en la toma de decisiones en detrimento de aquéllos y del resto de instituciones europeas.

Esta reforma se ha llevado a cabo a través de fórmulas mixtas o, como ha manifestado con gran tino algún autor, a través de instrumentos político estratégicos y jurídicos ${ }^{6}$ desbordantes desde un punto de vista cuantitativo. Tales actuaciones - la perspectiva temporal así permite afirmarlocarecen de una operatividad práctica efectiva, pues no sólo no redundan en la consecución efectiva de los objetivos pretendidos —estabilización de las finanzas públicas y crecimiento económico-, sino que además generan otros problemas de trascendencia sustantiva: la burocratización excesiva del entramado comunitario a través de la proliferación de organismos;

Según esta autora: «El principio goza de un origen mixto, fruto de la conjugación entre el Derecho de la Unión y el Derecho estatal. La fuerza atractiva ejercitada por el principio alemán ha conquistado al Consejo Europeo y se ha extendido al ámbito intergubernamental de los otros Estados adscritos a la Unión Monetaria, representando la imitación la fuerza motriz de la circulación del modelo, que parte desde lo bajo, comprendido como el nivel legislativo estatal, a partir de un enfoque bottom up. Así, el principio de equilibrio circula desde el nivel nacional hasta el nivel de la Unión, donde se asume conforme a una lógica top down, vinculado con la fuerza y la operatividad propia de la supremacía de las normas supranacionales en los ordenamientos internos de los Estados miembros».

5 Véase A. EmBid Irujo, La Constitucionalización de la crisis económica, Madrid, Iustel (2012), p. 109.

${ }^{6}$ Véase A. BAR CENDÓN, «La reforma constitucional y la gobernanza económica de la Unión Europea», Teoría y Realidad Constitucional, núm. 30 (2012), p. 71. Para un estudio pormenorizado de estos instrumentos me remito, además de al autor anterior, a M. LóPEZ ESCUDERO, «Las innumerables reformas de la gobernanza económica de la zona euro», Revista General de Derecho Europeo, núm. 27 (2012); M. Á. Martínez LAGo, «La reforma del régimen jurídico de la estabilidad presupuestaria y el Tratado de Coordinación y Gobernanza en la Unión Económica y Monetaria», Noticias de la Unión Europea, núm. 330 (2012), pp. 105-120, y V. RuIz AlmENDRAL, «Estabilidad presupuestaria y reforma constitucional», Revista Española de Derecho Europeo, núm. 41 (2012), pp. 33-110. 
la incapacidad o falta de interés para aplicar a su propia estructura organizativa las políticas de austeridad que predica insaciablemente para los Estados que la integran ${ }^{7}$, o el déficit democrático que propicia la centralización en la toma de decisiones, las cuales se adoptan en un ámbito cada vez más reducido y menos abierto al debate público —-máxime si tenemos en cuenta que a los Parlamentos nacionales se les ha privado de la tradicional facultad de determinar libremente los presupuestos generales, mutando la soberanía presupuestaria en mera autonomía- ${ }^{8}$.

Muchas son las consecuencias derivadas del aparato de medidas confeccionadas. Sin embargo, por su entidad, la introducción de las llamadas golden rules o reglas de oro en las normas de cabecera de los sistemas jurídicos nacionales constituye la principal novedad que, con efecto vinculante o coactivo, se desprende del Tratado de Estabilidad, Coordinación y Gobernanza (TECG), ratificado por el Consejo Europeo en marzo de 2012 -si bien es en el Pacto por el Euro Plus, aprobado por el mismo órgano un año antes, donde dicho compromiso adquiere plasmación por vez primera-.

\section{CONFIGURACIÓN NORMATIVA DE LA ESTABILIDAD PRESUPUESTARIA EN NUESTRO PAÍS}

\section{La reforma constitucional de agosto de 2011: el renombrado art. 135}

Una de las características propias de nuestra reciente tradición jurídico-constitucional reside en la reticencia sistemática a la ejecución de modificaciones en la norma rectora. No obstante, podemos destacar dos puntos de inflexión —ambos en clave europea - de los cuales únicamente el

7 Recordemos que la propia Comisión Europea, en pleno apogeo de la crisis económica (año 2011), pretende incrementar el salario de los comisarios y de los funcionarios europeos en un 1,7 por 100. Esta propuesta es vetada por el Consejo de la Unión, generando una controversia de pareceres que resuelve el TJUE (Sentencia de 19 de noviembre de 2013) desautorizando - con toda lógica- dicho incremento.

${ }^{8}$ Véase A. GARCía-Moncó, «Déficit, deuda pública y soberanía financiera: la reforma del art. 135 de la Constitución», en VVAA, La constitucionalización de la estabilidad presupuestaria, Madrid, Instituto de Derecho Público-Universidad Rey Juan Carlos (2012), p. 142; E. Álvarez CONDE, «Presentación de la reforma (preventiva) constitucional de 2011», en VVAA, La constitucionalización de la estabilidad presupuestaria, Madrid, Instituto de Derecho Público-Universidad Rey Juan Carlos (2012), pp. 26 y 34, y Á. Rodríguez BeREIJO, «La reforma constitucional del art. 135 y la crisis financiera del Estado», Otrosí. Revista del Ilustre Colegio de Abogados de Madrid, núm. 11 (2012), pp. 7 y 11. 
segundo materializa una variación sustancial del texto aprobado en 1978. Tal circunstancia ha suscitado numerosas reacciones y manifestaciones desde diferentes sectores sociales, entre los cuales la doctrina científica ha sido prolífica, aportando valoraciones críticas de lege lata y recomendaciones o propuestas de lege ferenda.

Mucho se ha especulado sobre las razones que han auspiciado este cambio en la norma normarum, llegando a hablarse de causas confesadas e inconfesadas ${ }^{9}$. No parece difícil colegir, en todo caso, que tras la imperiosa necesidad de actuar con premura radica una taimada y pertinaz presión ejercida desde diferentes instancias —el eje franco-alemán, los mercados internacionales y el Banco Central Europeo (BCE)_, especialmente teniendo en cuenta que la obligación establecida en el TECG es posterior en el tiempo y, por tanto, desde un punto de vista jurídico — que no político-, no existe fundamento alguno para su imposición.

En lo que respecta a las cuestiones formales, si bien ha existido un amplio consenso en cuanto a la elección del procedimiento, la tramitación parlamentaria ha sido clamorosamente deficiente ${ }^{10}$. En lo atinente a las cuestio-

9 Véase Piedad García-Escudero MárqueZ, «Sobre la reforma del art. 135 de la Constitución Española», Crónica Presupuestaria, núm. 1 (2013), pp. 95-96.

${ }^{10}$ En el Congreso de los Diputados se han utilizado de forma conjunta los procedimientos legislativos especiales de lectura única y de urgencia sin existir motivación alguna que respaldara la utilización de ambos, de dudoso encaje — por otro lado- si atendemos a la redacción literal de los arts. 150.1 y 93 de su Reglamento; se han rechazado la totalidad de las enmiendas presentadas y se ha prescindido de la participación preliminar de los órganos consultivos de coordinación de las haciendas territoriales y de la propia ciudadanía. En relación con esta última cuestión, me parece sumamente reprochable la argumentación de J. F. LÓPEz AguilaR, «De la Constitución irreformable a la reforma constitucional exprés», Teoría y Realidad Constitucional, núm. 29 (2012), pp. 215-216, que justifica la omisión del recurso al referéndum aduciendo que «la Constitución desconfía de la llamada a la democracia directa y, en consecuencia, administra con cautela el recurso al mismo por razones bien sólidas: suelen ser costosos y potencialmente divisorios, inevitablemente tensionan y son imprevisibles y confusos en cuanto a sus resultados cuando lo que se somete a consulta de la ciudadanía no es una pregunta directa, sino un texto técnico de varios apartados como el de esta reforma constitucional. Si no son absolutamente necesarios, por pertenecer a la parte de la Constitución que define nuestro Estado constitucional, o políticamente convenientes, cuya apreciación deja en manos del gobierno, lo razonable es acudir a las mayorías parlamentarias cualificadas, al igual que hacen prácticamente la mayoría de las Constituciones de nuestro entorno». Creo que en un contexto como el actual, donde el descrédito político —al menos de los «partidos tradicionales»— es una realidad palmaria y tangible, debería potenciarse la utilización de los sistemas —escasos, sí, pero existentes- de democracia directa. Es vergonzante que políticos como el que aquí se referencia —no es el único, ni mucho menos- utilicen la Constitución de escudo para justificar su propia desconfianza hacia la ciudadanía, mostrándose partidarios de sustituir la opinión popular por la de un líder o mayoría parlamentaria «cualificados», capaces de pensar y actuar por aquéllos, presumiendo que no tienen la suficiente madurez o cognoscibilidad para hacerlo por sí mismos. 
nes sustantivas o materiales, se han conservado algunos aspectos de la regulación primitiva - la necesaria autorización legal para emitir deuda pública y la mención expresa de que los créditos para satisfacer el pago de intereses y capital de los empréstitos se entenderán incluidos en el estado de gastos de los presupuestos, sin poder ser objeto de enmienda o modificación mientras se ajuste a la ley de emisión-y se han introducido algunas novedades relevantes - la elevación a rango constitucional del principio de estabilidad presupuestaria, la prioridad absoluta en el pago de los servicios de deuda de las diferentes Administraciones Públicas (AAPP) y la determinación de unos niveles de déficit estructural permitido al Estado y a las Comunidades Autónomas (CCAA) dentro de los márgenes establecidos en la Unión Europea (UE), salvo en caso de concurrencia de circunstancias excepcionales -

Sin entrar en disquisiciones cabalísticas, podemos enunciar una serie de conclusiones dimanantes de esta reforma. La misma resulta excesivamente abierta — no contiene una definición de estabilidad presupuestaria y emplea conceptos jurídicos indeterminados para delimitar los supuestos excepcionales en los que podrán sortearse los límites fijados-, redundante -incluye afirmaciones expresas que no añaden novedad alguna, como el hecho de que las CCAA (del mismo modo que el Estado) deberán estar autorizadas por ley para emitir deuda pública o contraer crédito-, farragosa - no sólo por la desmesura y prolijidad del nuevo cuerpo del precepto, sino también porque establece remisiones al Derecho europeo para determinar los límites de déficit y deuda pública (en este último caso aludiendo expresamente al TFUE, lo cual puede generar problemas en caso de una hipotética reforma del Derecho originario, chocando con el carácter rígido de la Constitución)—, innecesaria — habría bastado con una modificación de la normativa precedente en materia de estabilidad presupuestaria, de la Ley Orgánica de Financiación de las Comunidades Autónomas (LOFCA) o de las correspondientes Leyes de Presupuestos para conseguir efectos jurídicos análogos, o incluso ni eso, pues resultaban suficientes las limitaciones ya previstas en el marco comunitario, dado su carácter prevalente y su aplicación directa- y contraproducente — pues dispone que el pago de los intereses y el capital de la deuda pública gozarán de prioridad absoluta

Hago mías las palabras de otro insigne constitucionalista, M. CONTRERAS CASADO, «Encuesta sobre la reforma de la Constitución», Teoría y Realidad Constitucional, núm. 29 (2012), p. 16: «Si no fuera mucho pedir a los partidos políticos, sería deseable, cuando algún día esto suceda, que la reforma de nuestra Constitución fuera llevada a cabo de forma más seria y meditada, desde el punto de vista participativo y procedimental, que la última urgencia estival que modificó nuestra Constitución por segunda vez». 
en relación con cualquier otra obligación económica. Esto no sólo genera una situación de desigualdad entre acreedores totalmente injustificada ${ }^{11}$, sino que además condiciona la realización de otros derechos consagrados en el mismo cuerpo normativo, que, a mayor abundamiento, se erige en norma suprema de nuestro ordenamiento jurídico-.

\section{El desarrollo normativo y la problemática estructura del Estado plurilegislativo «indefinido»}

\section{A) Cuestiones preliminares: a vueltas con el modelo territorial}

Una vez más se pone de manifiesto, incidentalmente, el eterno debate sobre la singularidad de nuestro modelo territorial y la difícil conceptualización y acomodo que en el mismo presenta el principio de competencia. En opinión de Manuel Aragón Reyes «[tal principio] no es capaz por sí solo de articular perfectamente la distribución de poder y ofrecer la solución de todos los conflictos que en un ordenamiento territorialmente complejo se presentan». Para este autor «nuestro sistema de distribución territorial conduce tendencialmente a una situación de competencias generalmente concurrentes, lo cual significa que el principio de cooperación es más necesario que en otros Estados federales o regionales. El nuestro ha descentralizado su poder político en grado superior al de aquéllos, pero al mismo tiempo impone, también con mayor motivo, la coordinación territorial y la lealtad institucional. Este modelo compuesto posee ventajas —como la flexibilización o la posibilidad de asimetrías basadas en hechos diferenciales- e inconvenientes —el alto grado de indefinición competencial, fundamentalmente- . Por ello, la ley estatal y la autonómica se encuentran en una relación que lo es más de coordinación que de diferenciación. Son normas complementarias y no aisladas entre sí, siendo ésta una característica propia del modelo de organización que hemos construido» ${ }^{12}$.

${ }^{11}$ Véase A. GARCÍA-Moncó, «Déficit, deuda pública y soberanía financiera...», op. cit., pp. 140-141: «La inclusión de este inciso se formula en términos excesivos e innecesarios. Excesivos porque el Estado español debería tener otras prioridades y mucho más si son absolutas. E innecesarios porque con la regulación constitucional precedente España nunca dejó de satisfacer el servicio de deuda y existía un grado suficiente de vinculación jurídica, pues al iniciarse la elaboración de los Presupuestos dicha partida se incluía inexorablemente en los mismos».

${ }^{12}$ Véase M. Aragón Reyes, «La Ley Autonómica (a Luis Díez-Picazo y Ponce de León)», Revista Jurídica de la Universidad Autónoma de Madrid, núm. 6 (2002), pp. 26, 31, 35 y 36. 
Coincido plenamente con esta idea. El punctum dolens de la cuestión reside en la ausencia de coordinación territorial y de lealtad institucional entre los diferentes niveles de Administración, auténticas exigencias derivadas de nuestra estructura normativa y distribución competencial. Estamos ante un problema político -o mejor dicho, de voluntad políti$\mathrm{ca}$ - que se vislumbra de forma palpable y que dificulta en muchas ocasiones el encaje pacífico entre la legislación estatal y la autonómica sobre una misma materia.

El campo de la estabilidad presupuestaria es una clara muestra de ello. Frente a la indiscutible preponderancia que se otorga al Estado, el último párrafo del art. 135 de la Constitución (CE) propugna que las CCAA adopten las disposiciones que procedan para la aplicación efectiva del mismo en sus normas y decisiones presupuestarias, de acuerdo con sus respectivos Estatutos de Autonomía y respetando los límites constitucionales - y, por extensión, lo establecido en la ley orgánica que desarrolla estos últimos, atendiendo a su vocación funcional-. No se dice expresamente que, en observancia y garantía de dicho principio, deban aprobar normas ad hoc, aunque tampoco se veta tal posibilidad, dado lo ambiguo de la fórmula utilizada. Ningún problema se hubiera planteado pues si, en cumplimiento de lo dispuesto en la CE, las entidades territoriales indicadas se hubieran limitado a introducir determinaciones concretas en las normas que hubiesen considerado oportunas, en aras de garantizar la ansiada estabilización de las cuentas. No ha sido así, o, por lo menos, no en la totalidad de los casos. Varias CCAA han aprobado legislación propia en la materia llamada a coexistir con la regulación estatal, cuyos dictados tendrán en todo caso carácter prevalente, pues cumple un propósito claramente armonizador ${ }^{13}$ —esta superioridad viene avalada, asimismo, por la jurisprudencia constitucional emanada a comienzos de presente decenio- ${ }^{14}$. Este planteamiento, que constituye en cierto modo una carte blanche a favor del gobierno central, debe ser tenido en consideración a la hora de abordar el análisis del conglomerado normativo que centra el objeto de este estudio.

13 Véanse M. Á. Martínez Lago, «La Ley Orgánica de Estabilidad Presupuestaria y Sostenibilidad Financiera: naturaleza, función y principios generales. Instrumentación de las reglas uméricas», $C P$, núm. 1 (2013), pp. 155, 156, 158 y 163, y J. I. Gorospe Oviedo, «La estabilidad presupuestaria de las Comunidades Autónomas y la reforma del art. 135 de la Constitución», en VVAA, La constitucionalización de la estabilidad presupuestaria, Madrid, Instituto de Derecho Público-Universidad Rey Juan Carlos (2012), pp. 346-347.

${ }_{14}$ SSTC 134/2011, de 20 de julio; 157/2011, de 18 de octubre; 185, 186, 187, 188 y 189/2011, de 23 de noviembre; 197, 198 y 199/2011, de 13 de diciembre, y 203/2011, de 14 de diciembre. 


\section{B) Legislación estatal y autonómica}

Como es sobradamente conocido, la Ley Orgánica 2/2012, de 27 de abril, de Estabilidad Presupuestaria y Sostenibilidad Financiera (LOEPSF), viene a desarrollar en tiempo y forma ${ }^{15}$ las líneas maestras perfiladas en la Carta Magna, superando algunas cuestiones de carácter técnico-normativo planteadas en etapas anteriores y conformando el marco de disciplina fiscal en el que ha de desenvolverse la actividad financiera del sector público español.

La regulación autonómica, por otro lado, representa una auténtica novedad en su género al no contar con precedente alguno. Por el momento son cinco las CCAA que han elaborado leyes específicas en sus respectivos ámbitos territoriales, que procedo a enumerar por orden cronológico de aprobación: la Ley 2/2011, de 16 de junio, de Disciplina Presupuestaria y Sostenibilidad Financiera de Galicia ${ }^{16}$ (LDPSFG); la Ley 6/2012, de 17 de mayo, de Estabilidad Presupuestaria de Cataluña (LEPC); la Ley 5/2012, de 7 de junio, de Estabilidad Presupuestaria de Aragón (LEPA); la Ley 7/2012, de 24 de octubre, de Estabilidad y Disciplina Presupuestaria de Castilla y León (LEDPCL), y la Ley 11/2012, de 21 de diciembre, de Estabilidad Presupuestaria y Sostenibilidad Financiera de la Junta de Comunidades de Castilla-La Mancha (LEPSFJCM).

${ }^{15}$ La tramitación parlamentaria de esta ley transcurre pareja a la del propio art. 135 CE del que trae causa - aunque el apoyo político es menor en este caso-. Muestra de ello es el escaso lapso de tiempo transcurrido desde su aprobación como anteproyecto de ley (Consejo de Ministros de 27 de enero de 2012) hasta su publicación en el BOE (30 de abril del mismo año, dos meses antes del plazo máximo fijado), así como la carente voluntad de diálogo y consenso mostrados durante su debate en las Cortes Generales por parte del gobierno: 1) Se presenta como proyecto de ley en el Congreso de los Diputados el 3 de marzo de 2012, evacuando el informe del Consejo de Estado dos días antes, y el día 8 del mismo mes la Mesa de la Cámara acuerda encomendar Dictamen por el procedimiento de urgencia a la Comisión de Hacienda y AAPP, fijando a su vez un plazo de enmienda de ocho días naturales, ampliado hasta en cuatro ocasiones. Se formulan 206 enmiendas al texto original, de la cuales sólo se admiten doce del propio GPP (BOCG, Congreso de los Diputados, núm. A-3-7, de 4 de abril de 2012). El 12 de abril se publica en el BOCG el Dictamen emitido por la Comisión de Hacienda y AAPP sobre el Proyecto de Ley, coincidiendo cronológicamente con su aprobación en el Pleno del Congreso. 2) En el Senado el texto corre la misma suerte. Se presentan 99 enmiendas de las cuales no se acepta ninguna, aprobándose el texto en esta Cámara sin introducir variación alguna (BOCG, Senado, núm. 49-407, de 27 de abril de 2012).

${ }_{16}$ Esta norma se promulga incluso con anterioridad a la propia reforma constitucional, circunstancia que ha venido planteando algunos problemas de contenido y remisión normativa ya subsanados. 
a) Criterios subjetivos de aplicación, objeto y principios rectores

La LOEPSF enuncia de forma expansiva que sus prescripciones serán de aplicación a todos los poderes públicos, de ahí que sea necesario acudir a su art. 2.1 para delimitar un concepto tan etéreo. Sin justificación aparente ${ }^{17}$ y desoyendo las recomendaciones del Consejo de Estado, el legislador español opta por incorporar la clasificación europea en detrimento de las categorías tradicionales de nuestra legislación presupuestaria - Ley 47/2003, de 26 de noviembre, General Presupuestaria, y Ley 6/1997, de 14 de abril, de Organización y Funcionamiento de las Administraciones Públicas-. En consecuencia, y parafraseando a Miguel Esparza Oroz, «debemos olvidarnos del concepto jurídico de Administración Pública y del ropaje formal para centrarnos exclusivamente en su comportamiento económico» ${ }^{18}$. Probablemente, tras esta opción política subyazcan razones de homogeneidad y simplificación contable; sin embargo, la técnica legislativa utilizada es francamente discutible. También se enmarcan dentro del ámbito subjetivo de la norma - fórmula residual del art. 2.2 LOEPSF- el resto de entidades públicas empresariales, sociedades mercantiles y entes de Derecho público dependientes de las AAPP no incluidas en el apartado anterior, dada su consideración de sector público, aunque con una serie de especificidades.

En la legislación autonómica la cuestión no suscita problemas relevantes. Algunas utilizan fórmulas genéricas (art. 1.3 LEPC) y otras más específicas, expresas (arts. 2.1 LEPA y 2.1 y 2.2 LEPSFJCM) o vía remisión (arts. 2.1 LDPSFG y 2 LEDPCL). Resulta llamativo que dos de estas leyes utilicen el criterio delimitador que distingue entre entes financiados o no mayoritariamente por ingresos comerciales. La explicación es sencilla. La LDPSFG se aprueba bajo la vigencia del Real Decreto Legislativo 2/2007 y sus determinaciones se orientan en función de dicho marco referencial,

${ }^{17} \mathrm{El}$ art. 1.3 del Reglamento (CE) núm. 223/96 del Consejo de la Unión Europea, de 25 de junio de 1996, relativo al Sistema Europeo de Cuentas Nacionales y Regionales (SEC 95), señala expresamente que «ningún Estado miembro está obligado a elaborar con arreglo a este sistema las cuentas destinadas a satisfacer sus propias necesidades». Esta disposición ha sido sustituida por el Reglamento (UE) núm. 549/2013 del Parlamento Europeo y del Consejo, de 21 de mayo de 2013, relativo al Sistema Europeo de Cuentas Nacionales y Regionales de la Unión Europea (SEC-2010), y lo aquí expuesto se contiene ahora en el art. 1.4 de este último. A mayor abundamiento véase Dictamen 164/2012, de 1 de marzo, del Consejo de Estado, sobre el Proyecto de LOEPSF: «Debe delimitar su ámbito subjetivo de aplicación por referencia a las categorías vigentes en el ordenamiento interno».

${ }_{18}$ Véase M. EsParza OrOZ, «El nuevo marco de la estabilidad presupuestaria en España», Revista Parlamentaria de la Asamblea de Madrid, núm. 26 (2012), p. 175. 
que partía de tal clasificación. La LEPA simplemente constituye una mera copia de la anterior, pues se dedica a transponer su contenido sin idear e implementar criterios propios y sin cuestionarse que la ley de la que parte se aprueba en un contexto normativo sustancialmente diferente.

El objeto de la LOEPSF radica en la pretensión de alcanzar la consecución de un triple objetivo: garantizar la sostenibilidad financiera de todas las AAPP, fortalecer la confianza en la estabilidad de la economía española y reforzar el compromiso de España con la Unión Europea en materia de estabilidad presupuestaria (exposición de motivos y art. 1). En términos coincidentes, aunque con formulaciones diferenciadas, se enuncian las diferentes normas autonómicas.

Estos fines se instrumentalizan a través de una serie de principios rectores, vinculantes para los poderes públicos: estabilidad presupuestaria (art. 4 LOEPSF); sostenibilidad financiera (art. 3 LOEPSF); plurianualidad (art. 5 LOEPSF); transparencia (art. 6 LOEPSF); eficiencia en la asignación y utilización de los recursos públicos (art. 7 LOEPSF); responsabilidad (art. 8 LOEPSF), y lealtad institucional (art. 9 LOEPSF). Sin entrar a analizar su contenido, ya hay quien se ha ocupado de ello ${ }^{19}$, sí que me gustaría establecer algunas valoraciones acerca del tratamiento de esta cuestión por parte de la normativa autonómica.

La LDPSFG y la LEPA dedican los art. 3 a 8 al desarrollo individualizado de sus respectivos principios informadores, que coinciden grosso modo con los de la ley estatal; la LEPC únicamente hace referencia a la estabilidad presupuestaria en sus arts. 2.2 y 4 -no exentos de polémica— ${ }^{20}$, y la

19 Véanse M. Fernández CurRás, «Principios rectores de la Ley Orgánica de Estabilidad Presupuestaria y Sostenibilidad Financiera», en VVAA, Estabilidad presupuestaria y sostenibilidad fiscal, Madrid, Instituto de Estudios Fiscales (2013), pp. 13-20; J. M. DomínGUEZ MARTíNeZ y J. M. LÓPEZ JimÉNEZ, «La reforma de la política de estabilidad presupuestaria en España: análisis de la Ley Orgánica de Estabilidad Presupuestaria y Sostenibilidad Financiera», Documentos de Trabajo (Instituto Universitario de Análisis Económico y Social de la Universidad de Alcalá), núm. 9 (2012), pp. 32-37, y M. Á. MARTínez LAGO, «La Ley Orgánica de Estabilidad Presupuestaria...», op. cit., pp. 166-175.

20 Ambos preceptos han generado controversias, poniéndose en entredicho su constitucionalidad. Me limitaré aquí a abordar la problemática que plantea el art. 2.2 (pospongo la del art. 4 al momento posterior oportuno), que si bien no parte de unos parámetros normativos distintos a los de la LOEPSF para definir la estabilidad presupuestaria, sí prescinde de la referencia expresa a la misma, considerando el Consejo de Estado (Dictamen 803/2012, de 26 de mayo) que tal omisión podría conducir a una eventual actividad legislativa autonómica en cuestiones que corresponden a la norma estatal — determinación de los límites de déficit estructural y volumen de endeudamiento- [apartado III.a) in fine]. Este argumento me parece bastante lábil y la afirmación un tanto aventurada, en consonancia con lo aducido por Miguel Herrero de Miñón en voto particular, quien sostiene con rotundidad que la 
LEDPCL y la LEPSFJCM contienen una remisión directa a los principios de la LOEPSF en sus arts. 1 y 3 , respectivamente, aunque esta última volviendo a enumerarlos expresamente. Parece absolutamente innecesario que la legislación autonómica regule principio general alguno. Dos son las razones que sostienen este argumento: la primera emana de la propia redacción del art. 135.6 CE, que establece imperativamente que las CCAA garanticen el principio de estabilidad presupuestaria en sus respectivos ordenamientos jurídicos como finalidad implícita impresa en cada una de sus normas y decisiones, tratándose de una función coadyuvante para la consecución de un objetivo global e integral. Esa función de colaboración debe ejercitarse bajo unos criterios de coordinación, cuya determinación corresponde verdaderamente a la LOEPSF en cumplimiento de la labor específica que le atribuye la CE y que no puede realizar ninguna otra ley. Por ello, la fórmula más adecuada sería la utilizada por la LEDPCL, que remite genéricamente a los principios de aquélla, obviando cualquier referencia en su propio texto a los mismos - lo contrario constituye un exceso y contraviene el carácter armónico que debe prevalecer en este tipo de legislación-. La segunda, íntimamente ligada a la anterior, tiene que ver con la hiperactividad del legislador autonómico, muy dado en ocasiones al copia y pega de legislación estatal. Más allá de lo acertada o no que pueda resultar esta forma de proceder, lo cierto es que puede generar problemas sobrevenidos en caso de modificarse la normativa que se reproduce, ya que su uso se ampara en no pocas ocasiones en la falta de competencia específica.

Llama la atención, en último término, el hecho de que en la mayoría de las legislaciones autonómicas la referencia al principio de lealtad institucional brille por su ausencia —únicamente lo nombran las leyes castellanas, una expresamente y otra por remisión directa a la LOEPSF-. Quizás esta ausencia de mención sea intencionada, viniendo a constatar abiertamente lo expuesto en líneas precedentes.

ley catalana no utiliza parámetros distintos a la Constitución ni a la legislación estatal para definir la estabilidad presupuestaria, entendida como la situación de equilibrio o superávit estructural (art. 3.2 LOEPSF). Sí que existen, en cambio, motivos fundados para concluir que los arts. 6 y 9 LEPC contravienen, en su redacción original, el marco normativo referenciado, pues prevén un objetivo de estabilidad presupuestaria del 0,14 por 100 del PIB para el año 2018, de tal forma que durante el periodo transitorio 2012-2017 los Presupuestos de la Generalidad deberán elaborarse conforme a este objetivo [apartado III.d)]. La Ley [Cataluña] 2/2014, de 28 de enero, de Medidas Fiscales, Administrativas y Financieras del Sector Público, otorga una nueva redacción a estos artículos, evidenciando un apercibimiento parcial de las recomendaciones del máximo órgano consultivo español, pues incluye la referencia al cumplimiento de los objetivos de la legislación estatal pero sin renunciar al límite propio, cuyo cumplimiento difiere a 2019. 
b) Reglas fiscales

La fijación de límites numéricos sobre determinados agregados presupuestarios constituye, sin ningún género de dudas, el elemento nuclear y estratégico en el que descansa el ansiado fin estabilizador de las cuentas públicas, que a su vez se considera requisito sine qua non para la mejora integral de la situación económica general. Tres son los indicadores en los que inciden estas restricciones:

1) Déficit estructural. A los efectos de la LOEPSF se entenderá por déficit estructural «el ajustado al ciclo neto de medidas excepcionales y temporales» (art. 11.2 de la misma) ${ }^{21}$. Se prevé pues una situación presupuestaria de equilibrio o superávit para el Estado y las Comunidades Autónomas ${ }^{22}$ que únicamente podrá sortearse en dos supuestos muy concretos: reformas estructurales con efectos presupuestarios a medio plazo, en cuyo caso podría llegarse al 0,4 por 100 —si bien plantea problemas de indeterminación a la hora de delimitar el reparto entre Estado y CCAA en estos supuestos tolerados de desviación presupuestaria- ${ }^{23}$ (mismo art. 11.2

${ }^{21}$ Véase Á. Rodríguez BEREIJO, «La reforma constitucional del art. 135 y la crisis financiera del Estado», CP, núm. 1 (2013), pp. 26-27, para quien el propósito de esta medida no es otro que el de que «las AAPP no basen el equilibrio de sus cuentas públicas en ingresos coyunturales excesivamente dependientes del ciclo económico, como ha ocurrido en los años del ciclo expansivo de la economía española, lo que les llevó asumir compromisos de gasto que no podían cubrirse con los ingresos ordinarios de su hacienda».

${ }^{22}$ Las CL, en cambio, deberán mantener una situación de equilibrio o superávit presupuestario (art. 135.2, párrafo segundo in fine, de la Constitución española y art. 11.4 LOEPSF). Existen argumentos a favor y en contra de este tratamiento diferencial. Véase J. García Roca y M. Á. Martínez LaGo, Estabilidad presupuestaria y consagración del freno..., op. cit., p. 86, y F. De la HUCHA CELADOR, «La reforma del art. 135 de la Constitución: estabilidad presupuestaria y deuda pública», Revista Española de Derecho Financiero, núm. 153 (2012), pp. 3 y 31, respectivamente. La misma situación se prevé para las Administraciones de Seguridad Social, aunque se admite que puedan incurrir en déficit estructural de acuerdo con las finalidades y condiciones previstas en la normativa del Fondo de Reserva de la Seguridad Social, minorando en tal caso el déficit máximo permitido al Estado (art. 11.5 LOEPSF).

23 Véase R. FAlcón y TelLA, «La reforma del art. 135 de la Constitución», Revista General de Derecho Europeo, núm. 25 (2011), pp. 5-6: «Los límites de endeudamiento impuestos han hecho surgir en todos los países nuevos modelos de financiación de obra pública que escapan a los mismos y que cuentan con la anuencia de las instituciones comunitarias. Lo que ha dado lugar al perfeccionamiento de una serie de operaciones diferidas en el tiempo y que, en consecuencia, quedan fuera del perímetro de consolidación del déficit, ya que el ente público sólo considera gastos los pagos realizados dentro de cada ejercicio». En el mismo sentido, R. FERNÁNDEZ LleRA, «Colaboración público-privada como elusión de la estabilidad presupuestaria», Revista de Estudios Regionales, núm. extraordinario 86 (VIII) (2009), pp. 338-346: «La proliferación y uso de estos mecanismos trae causa de la propia debilidad 
LOEPSF), y concurrencia de catástrofes naturales, recesión económica grave o situación de emergencia extraordinaria, apreciada por la mayoría absoluta del Congreso (art. 11.3 LOEPSF) ${ }^{24}$. Esta opción legal es respetuosa tanto con el mandato constitucional — que omite cualquier referencia a cifras concretas, aunque de su dicción literal se desprende claramente la voluntad de establecer cierto margen de déficit estructural en la legislación de desarrollo- como con los límites máximos establecidos en el Derecho comunitario ${ }^{25}$. La legislación autonómica es respetuosa con estas prescripciones, aunque esto no ha sido así siempre ${ }^{26}$.

2) Techo de gasto. Se impone un límite de gasto no financiero que deberá ser tomado como referencia por los diferentes niveles de Administración ${ }^{27}$ para elaborar sus respectivos presupuestos (art. 12.1 LOEPSF).

de las fuentes tradicionales de financiación, y llama a extremar los controles para evitar que los mismos se conviertan en vehículos espurios de encubrimiento de deuda».

${ }^{24} \mathrm{El}$ art. 8 LEPC plantea nuevamente aquí un problema de encaje con la normativa estatal por dos motivos: 1) tiende a flexibilizar los límites de déficit/deuda pública y atenúa el alcance de los efectos previstos en la misma; 2) atribuye al Parlamento catalán la competencia para apreciar la incidencia de la situación excepcional en las cuentas de la Generalidad. En ambos casos, la solución interpretativa esgrimida por el Consejo de Estado [Dictamen 803/2012, de 26 de mayo, apartado III.d)] parece la más cabal. En relación con la primera cuestión, la legislación catalana formula referencias meramente descriptivas, asumiendo en todo caso que las funciones de configuración y caracterización legal corresponde a la LOEPSF. En relación con la segunda, el tenor literal de la ley estatal es sumamente claro, correspondiendo al Congreso de los Diputados la constatación de la situación descrita; cualquier otra interpretación conculcaría la CE.

${ }^{25} \mathrm{El}$ art. 3.1.b) y d) TECG determina para las partes contratantes una situación presupuestaria de equilibrio o de superávit estructural del 0,5 por 100 del PIB a precios de mercado, pudiendo ampliarse hasta un 1 por 100 del PIB cuando la proporción entre la deuda pública y el PIB a precios de mercado esté por debajo del 60 por 100 y los riesgos para la sostenibilidad a largo plazo de las finanzas públicas sean bajos.

${ }^{26}$ Dos CCAA, la LDPSFG y la LEPA, promulgan sus respectivas normas recogiendo definiciones de déficit estructural contrarias a la LOEPSF — la primera por razones lógicas, pues, como ya se ha indicado, es anterior a aquélla; la segunda por pura mala praxis legislativa, pues copia el texto de la anterior introduciendo pequeñas modificaciones sin lógica aparente que no garantizan su adecuación al nuevo marco legal imperante- . Sendas leyes de acompañamiento - la Ley [Galicia] 12/2014, de 22 de diciembre, de Medidas Fiscales y Administrativas, y la Ley [Aragón] 2/2014, de 23 de enero, de Medidas Fiscales y Administrativas - enmiendan esta cuestión suprimiendo y reformulando la redacción original de determinados preceptos. La LEPC, por su parte, introduce el concepto de saldo presupuestario estructural (art. 4.2), que también suscitó recelos por su similitud con el concepto de déficit estructural contenido en la LOEPSF. Sobre esta cuestión se ha pronunciado el Consejo de Estado [a través del ya citado Dictamen 803/2012, de 26 de mayo, apartado III.b)] considerando que, aunque la nomenclatura y definiciones de ambos coincidan, no parece que el precepto autonómico pretenda inaplicar la regulación estatal.

${ }_{27}$ Esta regla, que ahora se hace extensible a las CCAA, ya se introdujo para el Estado y las EL a través de la LGEP 2001 y su normativa de desarrollo. 
Su cálculo corresponde al Ministerio de Economía y Hacienda (MINECO), previa consulta de otras instituciones nacionales y europeas, tomando como referencia la tasa de referencia de crecimiento del PIB de medio plazo de la economía española (art. 12.3 LOEPSF). También aquí encontramos dos excepciones a la regla general: la existencia de un desequilibrio estructural en las cuentas públicas o una deuda superior al objetivo establecido, en cuyo caso el crecimiento del gasto público se ajustará a la senda establecida en los respectivos planes previstos (art. 12.1 in fine), y los eventuales efectos derivados de posibles cambios normativos que supongan aumentos permanentes o disminuciones de recaudación (art. 12.4) ${ }^{28}$.

3) Límite de deuda pública. Por primera vez se establece una limitación al endeudamiento, que no podrá superar el 60 por 100 del PIB, a razón de: 44 por 100 para la Administración central, 13 por 100 para el conjunto de las CCAA — cuya deuda, además, no podrá superar el 13 por 100 de su PIB regional-y 3 por 100 para la totalidad de Corporaciones Locales $(\mathrm{CL})$; proporciones que habrán de respetarse necesariamente en caso de variación del límite de deuda resultante (art. 13.1 LOEPSF). $\mathrm{El}$ incumplimiento de estos topes conlleva la interdicción de realizar operaciones de endeudamiento neto (art. 13.2 LOEPSF), no pudiendo superar la deuda pública emitida el saldo vivo existente al inicio del ejercicio presupuestario. Esta restricción no rige si nos encontramos ante algunas de las circunstancias excepcionales ya citadas (art. 13.3 en relación con el art. 11.3 LOEPSF). Nada aportan las reiteraciones relativas a la autorización legal para emitir deuda o contraer crédito ni a la prioridad absoluta del pago de deuda (arts. 13.4 y 14 LOEPSF, 7 LEPC y 11 LEDPCL). Mayor interés despierta la regulación contenida en el art. 13, apartados 4 in fine y 5, que refuerza el ejercicio de la supervisión estatal sobre las CCAA y de éstas —o aquél- sobre las CL, condicionando la autorización al cumplimiento de los objetivos, principios y obligaciones que se deriven de esa ley ${ }^{29}$.

${ }^{28} \mathrm{El}$ art. $135 \mathrm{CE}$ no hace referencia alguna a la regla de gasto y la propia exposición de motivos de la LOESPF tampoco aporta una justificación sólida al respecto. Esto ha suscitado un debate acerca de la existencia o no de habilitación constitucional que ampare esta previsión legal y de la posible vulneración de la autonomía financiera autonómica que de la misma pudiera derivarse. En tal sentido véase el Dictamen 8/2012, de 2 de julio, del Consell de Garantíes Estatutàires de Cataluña (pp. 40-42). En síntesis: «Esta regla de gasto es un complemento relevante para implementar el principio de estabilidad presupuestaria [sobre el que se cimenta] y para avanzar en la trayectoria hacia los objetivos de déficit y deuda que lo integran, existiendo pues una conexión suficiente entre ambos preceptos».

${ }_{29}$ Sobre el decepcionante reestreno de esta autorización — siguen permitiéndose ope- 
En términos análogos, parte de la legislación autonómica se compromete expresamente a respetar estos límites en pro de garantizar la sostenibilidad financiera de sus cuentas públicas (arts. 17 LDPSFG, 18 LEPA y 8 LEPSFJCM. A tal fin, esta última apuesta además, en su art. 9, por la creación de un Fondo de Reserva para la Deuda en sus presupuestos generales, figura diferente al destino finalista del superávit presupuestario, pero muy similar a la contenida en los arts. 5 LPCE y 10 LEDPCL).

Todo este entramado normativo debe interpretarse a la luz de la disposición transitoria $1 .^{a}$ y disposición final 7. ${ }^{a}$, párrafo segundo, ambas de la LOEPSF, según las cuales los niveles de déficit ${ }^{30}$ y deuda pública se irán reduciendo progresivamente — con sendas revisiones en 2015 y 2018hasta el 1 de enero de 2020, fecha de entrada en vigor de los límites descritos (en el mismo sentido la DT 2. ${ }^{a}$ LDPSFG y art. 9 LEPA).

c) Instrumentación de las reglas fiscales

El primer lugar deben establecerse los objetivos de estabilidad presupuestaria y deuda pública globales para el conjunto de las AAPP (art. 15 LOEPSF). Este cometido corresponde al gobierno central y se adopta mediante acuerdo del Consejo de Ministros - a propuesta del Ministerio de Hacienda y Administraciones Públicas (MHAP), previo informe del Consejo de Política Fiscal y Financiera (CPFF) y del Consejo Nacional de Administración Local (CNAL) en sus respectivos ámbitos- dentro del primer semestre de cada año. Posteriormente, se ordena su remisión a las Cortes Generales, junto con las recomendaciones e informes referidos en la ley, para su estudio y posterior aprobación o denegación, en cuyo caso se habilita un nuevo plazo máximo de un mes para que el gobierno remita un nuevo acuerdo que se tramite conforme al mismo procedimiento. Una vez aprobados, la observancia de estos objetivos se torna necesaria para las diferentes AAPP a la hora de elaborar sus proyectos de presupuestos.

raciones de endeudamiento aun incumpliéndose dichos objetivos- véase F. DE LA HuCHA CELADOR, «La deuda pública como recurso financiero en los distintos niveles de gobierno y sus limitaciones. El control del endeudamiento de las Administraciones Públicas», $C P$, núm. 1 (2013), pp. 266-268.

30 España se encuentra inmersa en un procedimiento de déficit excesivo [Decisión 2009/417/CE (DOUE, núm. L 135/15, de 30 de mayo de 2009)]; por ello, con base en lo estipulado en la DT 1. ${ }^{a} b$ ) in fine LOEPSF, su reducción debe adecuarse a lo exigido desde la Unión Europea. 
En este mismo convenio se incluye el límite de gasto no financiero del Presupuesto General del Estado, del que se informa al CPFF antes del 1 de agosto de cada año (arts. 15.1 in fine y 30.1 y 2 LOEPSF). Previsiones similares encontramos en las normas autonómicas, dado que, con pequeñas variaciones de matiz, establecen un procedimiento semejante para fijar los techos de gasto en sus respectivos presupuestos, del que deberán informar al CPFF también antes del 1 de agosto de cada año (arts. 12 LDPSFG, 11 LEPC, 13 LEPA, 7 LEDPCL y 6 LEPSFJCM, en relación con el art. 30.3 LOEPSF).

En segundo lugar, se procede al establecimiento de los objetivos individuales para las CCAA (art. 16 LOEPSF), correspondiendo al MHAP formular una propuesta en tal sentido - previo informe de la Autoridad Independiente de Responsabilidad Fiscal (AIRF) - y al gobierno la adopción de una decisión definitiva — previo informe del CPFF emitido en un plazo improrrogable de quince días, tomando como dies a quo el día de recepción de la propuesta del Ministerio- ${ }^{31}$. La redacción original de este artículo ha sido alterada para introducir la referencia a la AIRF, ocasión que podría haberse aprovechado para solventar —esta vez sí- los problemas de redacción latentes advertidos tempranamente por el Consejo de Estado ${ }^{32}$. Reza su contenido que la aprobación por parte del gobierno de los objetivos de estabilidad y deuda pública globales suponen requisito bastante para que se aprueben a su vez los mismos con carácter individual o singularizado. La ausencia de referencia alguna a la necesaria convalidación parlamentaria de los primeros como requisito sine qua non para poder determinar los segundos puede derivar en conclusiones absurdas, incoherentes y disparatadas. Ante tamaña antinomia, algunos autores han optado por una interpretación correctora ${ }^{33}$ - personalmente prefiero el término interpretación armonizadora- como posible solución.

En tercer y último lugar se elaboran y publican una serie de informes de cumplimiento (art. 17 LOEPSF) ${ }^{34}$ cuya elaboración corresponde tanto a

${ }^{31}$ De la propia exposición de motivos y del art. 18 de la LO 6/2013, de 14 de noviembre, de creación de la Autoridad Independiente de Responsabilidad Fiscal (LOAIRF), se desprende el carácter preceptivo de este informe.

32 Dictamen 164/2012, de 1 de marzo, del Consejo de Estado, sobre el Proyecto de LOEPSF, p. 39.

33 Véase J. García Roca y M. Á. Martínez Lago, Estabilidad presupuestaria y consagración del freno..., op. cit., p. 139.

34 Este precepto ha sido objeto de una intensa modificación por las implicaciones que sobre el mismo han tenido tanto la LOAIRF como la LO 9/2013, de 20 de diciembre, de Control de la Deuda Comercial en el Sector Público (LOCDCSP). Hay que recordar que en 
la AIRF como al MHAP — pudiendo este último, a su vez, esbozar recomendaciones a los realizados por el organismo independiente- $\mathrm{Al}$ primero corresponde elaborar, antes del 15 de octubre de cada año, un Informe sobre la adecuación al objetivo de estabilidad, deuda y regla de gasto del proyecto de los Presupuestos Generales del Estado (PGE) y de la información relativa a la implementación del principio de transparencia (art. 27 LOEPSF y Orden HAP/2105/2012, de 1 de octubre, por la que se desarrollan las obligaciones de suministro de información de dicha ley), y un Informe sobre el grado de cumplimiento de los objetivos de estabilidad presupuestaria y de deuda pública en los presupuestos iniciales de las AAPP, que recogerá también el cumplimiento de la regla de gasto de los presupuestos de la Administración Central y de las CCAA, siendo la fecha tope para su remisión al gobierno el 1 de abril de cada año. Al segundo le compete confeccionar y elevar al gobierno, antes del 15 de abril de cada año, un primer informe sobre el grado de cumplimiento del triple objetivo (déficit/ deuda/gasto) en el ejercicio anterior, en el que se refleja además la evolución real de la economía y las desviaciones respecto de la previsión inicial, y un segundo informe sobre el grado de cumplimiento del triple objetivo en el ejercicio anterior, que recoge las desviaciones producidas respecto de aquél y una previsión sobre el grado de cumplimiento en el ejercicio corriente y que elevará nuevamente al gobierno -informando además al CPFF y al CNAL, en sus respectivos ámbitos de competencia- antes del 15 de octubre de cada año (art. 20 LEPA).

\section{d) Medidas preventivas, correctivas y coercitivas}

En este apartado la LOEPSF traslada a nuestro ordenamiento jurídico la maquinaria comunitaria diseñada precisamente para garantizar el cumplimiento de los objetivos estabilizadores. Esta operación quirúrgica no está exenta de controversia no sólo por las dudas que puede suscitar el hecho de transponer soluciones normativas entre realidades político-territoriales plenamente diferenciadas, sino también por la dudosa estructura de supervisión que encumbra al gobierno español — y digo bien - frente a los del resto de Administraciones subcentrales, comprometiendo principios tales como la seguridad jurídica o la autonomía político-financiera.

su redacción primigenia, en la que el protagonismo recaía exclusivamente en el MHAP, los informes exigidos eran tres y no cuatro. 
Las medidas automáticas de prevención (art. 18 LOESPF) operan en primer término, previo seguimiento de los datos de ejecución presupuestaria, y consisten básicamente en la realización de ajustes en el gasto público con la firme intención de garantizar que al cierre del ejercicio no se incumpla el objetivo de estabilidad presupuestaria. Algunas son aplicables a todas las AAPP (limitación de las operaciones de endeudamiento a las de tesorería cuando el volumen de deuda pública de cada una de las mismas se sitúe por encima del 95 por 100 de los límites máximos ya mencionados en el presente trabajo) ${ }^{35}$; otras al Sistema de Seguridad Social (adoptar el establecimiento de los mecanismos de revalorización y ajuste que resulten necesarios mediante una norma con rango de ley para garantizar el equilibrio presupuestario y la sostenibilidad de este sistema ${ }^{36}$, y otra destinada a las CCAA y CL en materia de pago a proveedores (a grandes rasgos consiste en la formulación por parte del MHAP y del órgano interventor de la CL, respectivamente, de comunicaciones de alerta por incumplimiento del periodo medio de pago a proveedores —en los términos y plazos establecidos legalmente- en las que se indican el importe que deben dedicar mensualmente una u otra a tal fin y las medidas que tienen que adoptar con el propósito de generar tesorería necesaria para la reducción del mentado periodo de abono - en el caso de las CCAA, debe incluirse todo ello en su plan de tesorería; en el caso de las CL, esas medidas corresponden a la Administración que tenga atribuida su tutela financiera-. De resultar infructuosas, procede la retención de recursos derivados de la participación en tributos del Estado para satisfacer las obligaciones pendientes).

A lo ya expuesto añade el art. 19 LOEPSF que si se aprecia un riesgo de incumplimiento del triple objetivo de las CCAA y CL, el Gobierno central, a propuesta del MHAP, se dispondrá a formular una advertencia moti-

35 El 29 de diciembre de 2014 el Gobierno presenta en el Congreso de los Diputados un proyecto de ley orgánica de modificación de la LO 8/1980, de 22 de septiembre, de Financiación de las CCAA (LOFCA), y de la LO 2/2012, de 27 de abril, de Estabilidad Presupuestaria y Sostenibilidad Financiera (LOEPSF) —en el momento en que se escriben estas líneas el texto se encuentra en fase de ampliación de enmiendas al articulado- El mismo incorpora un inciso segundo al art. 18.1 LOEPSF en los siguientes términos: «Asimismo, harán un seguimiento del riesgo y coste asumido en la concesión de avales, reavales y cualquier otra clase de garantías que concedan para afianzar operaciones de crédito de personas físicas y jurídicas, públicas o privadas».

36 Este contenido ha variado por obra de la LOCDCSP, que ha suprimido la referencia a la aplicación automática del factor de sostenibilidad por parte del Gobierno en caso de que el sistema de pensiones proyecte un déficit a largo plazo, conforme a lo establecido en la Ley 27/2011, de 1 de agosto, sobre actualización, adecuación y modernización del sistema de pensiones. 
vada a la Administración responsable, previa audiencia de la misma, dando cuenta después de tal circunstancia al CPFF o a la CNAL — la misma se hace pública también para su general conocimiento-. Desde ese momento, la Administración advertida dispone de un mes para adoptar las medidas necesarias para evitar el riesgo. En caso de no obrar en tal sentido, o de considerar el MHAP que lo acordado resulta insuficiente, se activan automáticamente las medidas correctivas y coercitivas previstas en la ley.

Las medidas automáticas de corrección (art. 20 LOEPSF) ${ }^{37}$, previstas también para CCAA y CL, despliegan su eficacia en los casos en que el Gobierno central comprueba, con base en los informes ya reseñados, que efectivamente se ha producido un incumplimiento del triple objetivo y en el caso de desatención de la advertencia de riesgo de incumplimiento - reiterando lo prescrito en el precepto anterior aunque con un tono más lesivo, pues parece dar a entender que su operatividad será independiente de las medidas adoptadas por la Administración apercibida-. Consisten en imponer autorización estatal para todas las operaciones de endeudamiento autonómicas, salvo que dicha CA hubiese presentado un plan económicofinanciero considerado idóneo por el CPFF, en cuyo caso las operaciones de crédito a corto plazo que no sean consideradas financiación exterior no precisarán de la mencionada autorización ${ }^{38}$, y autorización del Estado - 0 CA que ejerza la tutela financiera-para todas las operaciones de endeudamiento a largo plazo de una CL. Además, se regula la emisión de un informe favorable por parte del MHAP para los supuestos de concesión de subvenciones o suscripción de convenios entre la Administración central y la CA incumplidora, cuyos criterios de elaboración establecerá la Ley de Presupuestos Generales del Estado ${ }^{39}$.

${ }^{37}$ La última parte del artículo (párrafos 5, 6 y 7) se introduce ex novo con la LOCDCSP.

${ }^{38}$ El ya aludido Proyecto de Ley Orgánica de modificación de la LO 8/1980, de 22 de septiembre, de Financiación de las CCAA (LOFCA), y de la LO 2/2012, de 27 de abril, de Estabilidad Presupuestaria y Sostenibilidad Financiera (LOEPSF), también incorpora variaciones en el art. 20 LOEPSF, introduciendo un tercer inciso en su párrafo primero en los siguientes términos: «Asimismo, la concesión de avales, reavalaes u otra clase de garantías a las operaciones de crédito de personas físicas o jurídicas, públicas o privadas, incluidas las entidades de la Comunidad Autónoma no incluidas en el ámbito de aplicación del art. 2.1.b) de esta ley, precisará de autorización del Estado. Esta autorización se podrá realizar de forma gradual por tramos de importes a avalar y garantizar, y será preceptiva hasta que el Ministerio de Hacienda y Administraciones Públicas constante que se ha cumplido el objetivo de estabilidad presupuestaria, de deuda pública o de la regla de gasto».

39 Véase A. NAvArRo Fauré, «La aplicación de las medidas correctivas de control de la estabilidad presupuestaria y sostenibilidad financiera a las subvenciones», REDF, núm. 164 (2014), pp. 61-77 in totum. 
Por último, se recogen algunas disposiciones en relación con el periodo medio de pago a proveedores de las CCAA para aquellos supuestos en los que las medidas automáticas de corrección no hayan surtido los efectos pretendidos en los plazos establecidos al efecto por la norma. El MHAP comunica entonces a la CA incursa en tal situación que, a partir de ese momento y durante los seis meses siguientes hasta que se ajuste al periodo medio de pago, deberá: i) promover la perfección de un acuerdo de no disponibilidad en la misma cuantía que las modificaciones presupuestarias que se realizan y que supongan un aumento neto del gasto no financiero de las CCAA y no se financian con cargo al fondo de contingencia o con baja en otros créditos (ese acuerdo se comunica al Ministerio indicando el crédito afectado, la medida de gasto que lo sustenta y la modificación presupuestaria que la origina); ii) someter a autorización estatal — pudiendo ser la misma gradual o por tramos - todas sus operaciones de endeudamiento a largo plazo; iii) incluir en la actualización de su plan de tesorería inmediatamente posterior nuevas medidas para cumplir con el plazo máximo de pago previsto en la normativa de morosidad. Si estas medidas no consiguen corregir las desviaciones existentes en el tiempo habilitado, el MHAP inicia el procedimiento de retención de los importes a satisfacer por los recursos de los regímenes de financiación para pagar directamente a los proveedores, recabando la información necesaria para ello y comunicándolo al CPFF para su conocimiento.

Junto a estas medidas, el incumplimiento del triple objetivo conlleva necesariamente la elaboración y presentación de un plan económico-financiero por parte de la Administración incumplidora con fines reparadores (art. 21 LOEPSF). También contempla la ley los planes de reequilibrio (art. 22 LOEPSF), previstos para aquellos supuestos en que el alejamiento de los objetivos sea consecuencia de la confluencia de las circunstancias excepcionales ya citadas (art. 23 LOEPSF), así como la tramitación y seguimiento de unos y otros (arts. 23 y 24 LOEPSF) ${ }^{40}$.

La cláusula de cierre de este armazón radica en las medidas coercitivas (art. 25 LOEPSF), auténticas sanciones que constituyen probablemente el

\footnotetext{
40 Sobre estas cuestiones véase M. Á. MarTínEZ Lago, «La Ley Orgánica de Estabilidad Presupuestaria y Sostenibilidad Financiera: estabilidad y supervisión de las reglas fiscales y corrección de los riesgos de incumplimiento», CP, núm. 2 (2014), pp. 142-144, y X. FERNÁNDEZ LEICEAGA, «La nueva normativa de estabilidad presupuestaria y sostenibilidad financiera y las Comunidades Autónomas», en La consolidación fiscal en España: el papel de las Comunidades Autónomas y los municipios (experiencias, retos y perspectivas), Madrid, Instituto de Estudios Fiscales (2013), p. 244.
} 
aspecto más innovador de esta normativa ${ }^{41}$. Cuando fracasan los métodos precedentes — por falta de presentación, aprobación o incumplimiento del plan económico-financiero o del de reequilibrio-, la Administración Pública dispone de quince días desde el incumplimiento constatado para aprobar la no disponibilidad de créditos y efectuar su correspondiente retención, detallando las medidas para ello e identificando el crédito presupuestario afectado que no puede ser revocado durante el ejercicio presupuestario en el que se aprueba o hasta la adopción de medidas que garanticen el cumplimiento del objetivo establecido. Incluso cabe la avocación del ejercicio de las competencias normativas que tienen atribuidas las CCAA en relación con los tributos cedidos a favor del Estado, siempre que resulte necesario para dar cumplimiento a los compromisos de consolidación fiscal comunitarios. Además, debe constituir un depósito en el Banco de Espa$\tilde{n} a$, cuando así se solicite por el MHAP, equivalente al 0,2 por 100 de su PIB nominal, cancelable en el momento en que se apliquen las medidas que garanticen el cumplimiento de los objetivos marcados. Si en el plazo de tres meses desde la constitución de la garantía indicada no se presenta o aprueba el plan o aplican las medidas, dichas cantidades depositadas devengan intereses. En cambio, si transcurre un nuevo plazo de tres meses y persiste el incumplimiento puede acordarse que la cantidad consignada se convierta en una multa coercitiva ${ }^{42}$ (esta fórmula se inspira claramente en los arts. 260 TFUE y 8.2 TECG). A falta de mención expresa en la ley, lo lógico sería pensar que el encargado de adoptar esa decisión sea el Gobierno de la nación.

En caso de no adoptarse las medidas relativas a la no disponibilidad de créditos o, adoptadas, resulten claramente insuficientes, el Gobierno procede al envío, bajo la dirección del MHAP, de una comisión de expertos para valorar la situación económico-presupuestaria de la Administración afectada — de la cual puede solicitar cualquier dato, información o

${ }^{41}$ Véase J. GarCía ROCA, «El principio de estabilidad presupuestaria y la consagración constitucional del freno al endeudamiento», CP, núm. 1 (2013), p. 74: «La responsabilidad por incumplimiento y las sanciones es una materia constitucional de la que debió ocuparse la reforma; entre otras razones, por un justo paralelismo con las disposiciones constitucionales de los arts. 153 y $155 \mathrm{CE}$ en materia de controles y por respeto al autogobierno y autonomía política y financiera de las CCAA».

42 Véase G. ORÓN MORATAL, «El control del equilibrio presupuestario en los distintos niveles de gobierno», CP, núm. 1 (2013), p. 202: «La ley no especifica el destino de las multas que puedan hacerse efectivas, por lo que siendo impuesta por el Estado, sin procedimiento sancionador contradictorio alguno - el receptor de información, el vigilante, se convierte a su vez en instructor, juzgador y ejecutor-, cabe pensar que se convertirán en ingreso estatal». 
antecedentes respecto a las partidas de ingreso y gastos- y debe presentar una propuesta de medidas y unas conclusiones públicamente en el exiguo plazo de una semana ${ }^{43}$, siendo sus decisiones de obligado cumplimiento para la Administración a la que van destinadas.

A mayor abundamiento, y como solución ultima ratio, la LOEPSF instaura unas medidas de cumplimiento forzoso (art. 26) diferenciadas en función de la Administración de destino: 1) Cuando la misma es una CA, el Gobierno español, de conformidad con lo dispuesto en el art. $155 \mathrm{CE}^{44}$, requiere al Presidente autonómico para que lleve a cabo en el plazo que se señale las medidas coercitivas enumeradas en el párrafo anterior. En el caso contrario, aquél, con la aprobación de la mayoría absoluta del Senado, adopta las medidas necesarias para obligar a su ejecución forzosa. 2) Cuando la misma es una CL, es el Gobierno español o la CA — cuando tenga atribuida la tutela financiera - la que requiere al presidente de aquélla para que adopte en el plazo que se indique las mismas determinaciones que en el supuesto anterior. Si aun así perdura el incumplimiento de alguna de las obligaciones solicitadas, podría considerarse una gestión gravemente dañosa para los intereses generales ${ }^{45}$, procediéndose a la disolución de los órganos de la CL incumplidora de acuerdo con el art. 61 de la Ley 7/1985, de 2 de abril, de Bases del Régimen Local (LBRL) ${ }^{46}$.

La normativa autonómica también contiene algunas consideraciones a este respecto (arts. 13 y 16 LDPSFG, 14 LEPA, 4 y 5 LEDPCL, y 13, 14, 15, 16 y 17 LEPSFJCM. Especial significación presenta esta última, pues, emulando a la propia LOEPSF, regula con sumo detalle un conjunto de medidas de seguimiento, control y corrección generales y específicas que inciden en las diferentes fases del presupuesto. Igualmente, diseña un sistema de aplicación forzosa parejo al estatal que abre la puerta

${ }^{43}$ En palabras del propio ministro de Hacienda y Administraciones Públicas, la visita de esta comisión de expertos, en caso de llevarse a cabo, no será precisamente amable, siendo su función semejante a la de la troika europea en los países intervenidos.

${ }^{44}$ Sobre el recurso al mismo véase J. GARCía TORRES, «El art. 155 de la Constitución española y el principio constitucional de autonomía», en Organización territorial del Estado, vol. II, Madrid, Instituto de Estudios Fiscales (1984).

${ }_{45}$ En este sentido, la Ley Orgánica 4/2012, de 28 de septiembre, introduce en la LOEPSF la disposición adicional $4 .{ }^{a}$, que dispone en su párrafo segundo que la situación de riesgo de incumplimiento del pago de los vencimientos de deuda apreciada por el gobierno a propuesta del MHAP se considera que atenta gravemente contra el interés general.

${ }^{46}$ Se trata de un supuesto sumamente excepcional. Si no recuerdo mal, únicamente ha sido utilizado en una ocasión (RD 411/2006, de 7 de abril, por el que se dispone la disolución del Ayuntamiento de Marbella, adoptado en Consejo de Ministros a solicitud de la Junta de Andalucía). 
a una futurible, hipotética y dudosa realidad de intervención al cubo o a tres niveles).

\section{e) Otras cuestiones complementarias}

La LOEPSF dedica también un capítulo a la instrumentación del principio de transparencia (arts. 27 y 28), que a día de hoy continúa siendo una de las grandes asignaturas pendientes de nuestra ya no tan joven democracia, a pesar de tratarse de un «requisito fundamental, puesto que sus beneficios son indudables y relevantes para asegurar la estabilidad presupuestaria y sostenibilidad financiera, para mejorar la credibilidad y la confianza en el funcionamiento del sector público, y para reforzar la democracia y la rendición de cuentas» ${ }^{47}$ (también arts. 19 y 20 LDPSFG, 10 LEPC, 19 y 20 LEPA, y 12 LEPSFJCM).

Finalmente, consagra varios elementos en materia de gestión presupuestaria tendentes a reforzar: 1) La planificación presupuestaria a medio plazo a través de un plan (art. 29 LOEPSF) en el que se enmarca la elaboración de los presupuestos anuales y se garantiza la programación presupuestaria coherente con los fines de la ley. Cualquier desviación debe ser explicada y motivada en aras de preservar el principio de estabilidad presupuestaria y sostenibilidad financiera (así se infiere de los arts. 15 LDPSFG y 16 LEPA). Este plan se incluye en el Programa de Estabilidad. En su redacción originaria la LOEPSF utilizaba una terminología diferente - marco presupuestario a medio plazo - que ha variado tras la reforma perpetrada por la LOCDCSP. Algunas CCAA conservan aquella denominación (arts. 12 LEPC y 5 LEPSFJCM), mientras que otras ya la han superado (arts. 11 LDPSFG y 12 LEPA). 2) El límite de gasto no financiero (art. 30 LOEPSF). 3) El fondo de contingencia (art. 31 LOEPSF) o dotación diferenciada que tienen que incluir tanto Estado, CCAA como CL en sus presupuestos para atender necesidades de carácter no discrecional y no previstas en el mismo ab initio — su cuantía y las condiciones de aplicación las determina cada Administración Pública en el ámbito de sus respectivas competencias— ${ }^{48}$, con la peculiaridad de que el remanente de

${ }^{47}$ Véase B. SESMA SÁNCHEZ, «El principio de transparencia presupuestaria», CP, núm. 1 (2013), p. 237.

${ }^{48}$ Con anterioridad a la aprobación de esta ley, las CCAA y CL no estaban obligadas a dotar este fondo, aunque entre las primeras algunas sí lo venían incluyendo de facto en sus cuentas públicas (Aragón, Cantabria, Cataluña, Galicia, Canarias o País Vasco). 
crédito que eventualmente pueda existir al final de cada ejercicio no puede ser objeto de incorporación a ejercicios posteriores (también lo regulan expresamente los arts. 15 LEPA y 7 LEPSFJCM). 4) El destino del superávit presupuestario (art. 32 LOEPSF) que, en caso de existir, se orientará a reducir el nivel de endeudamiento neto siempre con el límite del volumen de endeudamiento si éste fuera inferior al importe del superávit a destinar a la reducción de deuda. En el caso de la Seguridad Social, el superávit se aplicará prioritariamente al fondo de reserva con la finalidad de atender a las necesidades futuras del sistema ${ }^{49}$. También existen alguna referencias al destino del superávit de los entes instrumentales, financiados o no mayoritariamente con ingresos públicos (art. 10 LEPSFJCM) ${ }^{50}$.

\section{BALANCE}

El nuevo marco surgido al albor de las modificaciones legislativas expuestas y analizadas deja algunos frentes abiertos de intrincada solución. La tardía reacción ante la crisis deviene en un acelerado afán por enmendar el descuido y la desidia iniciales, alumbrando un panorama hipernormado e ignorando que la economía y los mercados suelen ser tremendamente reacios a ser administrados por dictados jurídicos. La adopción de soluciones a la carrera resulta casi siempre una apuesta arriesgada, pues es frecuente que las mismas no mitiguen los problemas que pretenden combatir y que, además, engendren otros nuevos con carácter sobrevenido.

49 Sobre el contenido primigenio de este precepto tuvo ocasión de pronunciarse el ya citado Dictamen 8/2012, de 2 de julio, del Consell de Garanties Estatutàries de Catalunya, pp. 45-48, matizando que «aunque no se puede negar que este destino del superávit impuesto podría ser recomendable en el marco de una política fiscal prudente, sobre todo en ejercicios en los que se ha experimentado una bonanza económica, eso no significa que el legislador orgánico pueda imponerla de forma imperativa y generalizada a las CCAA, sin distinguir los casos en los que es necesaria para alcanzar los objetivos de estabilidad presupuestaria de aquellos en que no lo es». Tras la emisión de este informe, la Ley 17/2012, de 27 de diciembre, de Presupuestos Generales del Estado para el año 2013, establece en su DA 74. ${ }^{a}$ que durante 2013 el gobierno, previo acuerdo con las asociaciones de entidades locales más representativas e informe de la CNAL, promoverá la modificación de este artículo con el fin de determinar y desarrollar las condiciones para posibilitar el destino finalista del superávit presupuestario de las mismas —las únicas que por el momento presentan tal resultado-. La LOCDCSP, siguiendo estos postulados, aporta una nueva redacción y resuelve los problemas interpretativos, introduciendo a su vez ex profeso la DA 6. a la LOEPSF, en la que se fijan una serie de reglas especiales para el destino del superávit presupuestario.

${ }^{50}$ Véanse también los arts. 14 y 16 LDPSFG y 17 LEPA en lo referente a su gestión y liquidación presupuestaria. 
La reforma constitucional, muy criticada desde los diferentes sectores sociales, acaba con la venerada y característica neutralidad de su texto, especialmente en su vertiente económica ${ }^{51}$. En agosto de 2011 se abre un debate, hasta la fecha inexistente, entre diferentes posiciones doctrinales polarizadas: de un lado, quienes sostienen que la fórmula utilizada supone una determinada opción por una concreta política económica ${ }^{52}$; de otro, aquellos que consideran que no estamos ante una decisión de carácter ideológico, sino ante una simple exigencia de la razón que no constriñe la libertad de elección política, pues no prescribe un equilibrio presupuestario stricto $\operatorname{sensu}^{53}$. No faltan tampoco quienes, desde posturas más eclécticas, defienden que la reforma se ubicaría en un punto intermedio entre las dos anteriores, si tal postura pudiera existir ${ }^{54}$. Para ser justos hay que reconocer que la CE tolera cierto margen de endeudamiento, aunque el mismo es muy limitado y en la mayoría de los casos se reconduce a supuestos excepcionales. Del mismo modo, cuestiona el Estado en su configuración social y democrática de Derecho, evidencia más que constatada en nuestros días. Puede que la reforma no suponga per se desmantelamiento alguno del modelo instaurado - no nazca con esa vocación finalista al menos-; sin embargo, cualquier afectación sobre el gasto que no conlleva aparejada una actuación sobre los ingresos genera disfunciones de esta naturaleza. La necesidad de reducir el déficit debe conjugarse indefecetiblemente con el mantenimiento del Estado de bienestar. Por último, se plantea un problema en absoluto desdeñable del que, con toda seguridad, no se apercibe el poder constituido-constituyente cuando perpetra este cambio en la norma normarum: el control de constitucionalidad sobre las finanzas públicas. Alguna noción al respecto contiene la LOEPSF en su disposición adicional 3. a , aunque aporta más sombra que luz, pues se limita a declarar la competencia del Tribunal Constitucional (TC) omitiendo cualquier referencia al que hasta ahora ha sido el

51 Véase J. E. Soriano García, Derecho público de la competencia, Madrid, Marcial Pons (1998), p. 79, y M. García Pelayo, «Consideraciones sobre las cláusulas económicas de la Constitución», en Estudios sobre la Constitución española de 1978, Zaragoza, Pórtico (1979), pp. 27-53 in totum.

52 Entre otros véanse M. Á. MartínEZ LAGO, «Crisis fiscal, estabilidad presupuestaria y reforma de la Constitución», El cronista del Estado Social y Democrático de Derecho, núm. 24 (2011), pp. 18-19; E. Álvarez ConDE, «Presentación de la reforma (preventiva) constitucional...», op. cit., p. 27, y E. AlberTi RoBIRA, «La reforma del art. 135 CE», Revista Española de Derecho Constitucional, núm. 93 (2011), p. 164.

53 Véase J. Tajadura Tejada, «Reforma constitucional e integración europea», Claves de Razón Práctica, núm. 216 (2011), pp. 20-28.

54 Véase M. Esparza OrOz, «El nuevo marco de la estabilidad presupuestaria...», op. cit., pp. 172-173. 
supremo órgano en materia de fiscalización de las cuentas y de la gestión económica, el Tribunal de Cuentas (TCu), que de facto puede seguir pronunciándose sobre estos temas amparándose en las funciones que le otorgan los arts. 136 y 153 CE. La situación de incertidumbre es notable y la necesidad de establecer planteamientos de control lógicos y estructurados, clamorosa. Para Álvaro Rodríguez Bereijo, «el control de constitucionalidad [...] se mueve en este campo, más que en ningún otro de la materia constitucional, en una permanente tensión entre los dos extremos de la deferencia frente al legislador democrático y a su legítima libertad de opción política [...] y la aplicación activista de los preceptos constitucionales que integran la Constitución económica (con el riesgo de sustituir autoritariamente las decisiones del legislador democrático, en su legítima libertad de opción política, por las del propio Tribunal)» $\gg^{55}$. Ya existe algún pronunciamiento reciente que evidencia la falta de altura del TC para enfrentarse a estas cuestiones y que tendré ocasión de abordar más adelante.

La sensación de desasosiego es mayor, si cabe, cuando uno analiza el desarrollo orgánico. La LOEPSF, que nace bajo la pétrea y diestra inclinación de garantizar la sostenibilidad financiera del conjunto de AAPP a través de la reducción del déficit y la deuda pública, denota una pasmosa improvisación. Muestra de ello es que, con apenas tres años de vida, ha experimentado ya tres modificaciones y va camino de la cuarta. Sirvan tres ejemplos representativos de lo aquí expuesto.

Primer ejemplo. La norma estatal aprobada en 2012 otorga un papel cualificado al MHAP, que se erige en una suerte de vigía omnipotente y omnicomprensivo de la estabilidad con un protagonismo incuestionable y excesivo - la supervisión política es pues la solución recogida en origen- . No obstante, en el marco del Derecho comunitario derivado se viene gestando la necesidad de encomendar este tipo de empresas a Administraciones Independientes como garantía de neutralidad y rigor técnico ${ }^{56}$, lo que doblega relativamente ese planteamiento inicial. Y digo relativamente porque si bien el Gobierno crea una Autoridad Independiente — al menos con carácter nominativo - cuya imparcialidad e inde-

55 Véase Á. Rodríguez BEREIJO, «La reforma del art. 135 y la crisis financiera del Estado», CP, núm. 1 (2012), p. 35.

${ }_{56}$ Véase la Directiva 2011/85/UE del Consejo, de 8 de noviembre, sobre los requisitos aplicables a los marcos presupuestarios de los Estados miembros, y el Reglamento 473/2013 del Parlamento y del Consejo, de 21 de mayo, sobre disposiciones comunes para el seguimiento y la evaluación de los proyectos de planes presupuestarios y para la corrección del déficit excesivo de los Estados miembros de la zona euro que integra el two pack. 
pendencia funcional se predican legalmente, la misma se adscribe al propio MHAP, circunstancia suficiente para dudar de las bondades de su logro — por lo menos con carácter preventivo—. Tampoco se erradica el exacerbado protagonismo del MHAP en el texto de la ley con la introducción de esta figura que, como ha señalado con gran acierto algún autor, era totalmente prescindible ${ }^{57}$, pues habría bastado con un ejercicio de recomposición institucional de la mano de la tan necesaria simplificación orgánico-administrativa, lo que a su vez habría sido más respetuoso con el vanagloriado principio de austeridad.

Segundo ejemplo. Tras la reforma constitucional, atestigua el propio Juan Fernando López Aguilar lo siguiente: «El gran objeto [de la misma] ha consistido en asegurar el compromiso del cumplimiento de sus obligaciones a todas las CCAA por igual, indiferenciadamente a los diferencialismos económico-sociales» ${ }^{58}$. La rotundidad a la hora de defender opiniones sobre cuestiones jurídicas sustancialmente politizadas no parece una opción demasiado prudente para quien, además, ha ocupado altas responsabilidad institucionales a nivel nacional y las sigue ostentando a nivel europeo. Esto demuestra la imprecisión de las decisiones políticas, que muchas veces resultan impredecibles hasta para quien las toma a diario. Para sorpresa de propios y extraños, en el año 2013 asistimos a lo que se viene a denominar déficit asimétrico. Frente a la tradicional determinación homogénea y unitaria de los objetivos de déficit y deuda entre las diferentes CCAA que integran el Estado español, se postula la posibilidad de que tal distribución se lleve a cabo de forma diferenciada para cada una de las mismas, teniendo en cuenta para ello una serie de criterios tales como el punto de partida de cada CCAA, el esfuerzo realizado por cada una y el acceso a los mercados para financiarse. El germen de este planteamiento radica en la reunión del CPFF de 21 de marzo de 2013, en la que Gobierno y CCAA debaten la creación de un grupo de trabajo para estudiar la posibilidad de que cada autonomía cumpla un déficit diferente, posibilidad que se implementa gracias al respaldo de la Comisión Europea a la flexibilización del porcentaje de déficit adjudicado a España —abril de

57 Véase M. Esparza Oroz, «El nuevo marco de la estabilidad presupuestaria...», op. cit., pp. 192-193: «Probablemente existan ya organismos en nuestro ordenamiento jurídico independientes o autónomos capacitados para realizar esta función, como, por ejemplo, el [preterido, esto es cosecha propia] Tribunal de Cuentas con la colaboración del Instituto Nacional de Estadística y el Banco de España».

${ }^{58}$ Véase J. F. LóPez Aguilar, «De la Constitución irreformable a la reforma...», op. cit., p. 213. 
2013 - con la consecuente prórroga de dos años - hasta 2016 - para cumplir el objetivo de rebasar a la baja el 3 por 100 del PIB. En la reunión del CPFF de 31 de julio de 2013 se consagra esta opción y se fijan los límites de déficit para cada CCAA. Esta medida sale adelante con los votos en contra de Madrid, Cataluña, Asturias y Canarias, mientras que Navarra, Aragón, Extremadura y Andalucía se abstienen — la consejera del País Vasco no se encuentra presente-. El 28 de marzo de 2014 el MHAP publica los datos de cumplimiento de déficit del año precedente. El resultado de este proyecto experimental no arroja los resultados pretendidos, circunstancia que propicia la vuelta al objetivo común del 1 por 100 del PIB para el año 2014 — por mucho que se empeñe el ministro en negar la mayor, los datos son contundentes- ${ }^{59}$. En un momento de crispación política como el presente, esta solución — aunque circunstancial— genera desigualdades y recelos interregionales innecesarios. La LOEPSF es ambigua en su redacción, circunstancia que otorga un amplio margen interpretativo y posibilita que soluciones como la aquí expuesta no sean contrarias a su tenor literal, lo que no significa que sean justas o procedentes desde un punto de vista teleológico o finalista.

Tercer ejemplo. Ante la coyuntura imperante en 2011, fecha en que los mercados dan la espalda a algunas AAPP, la disposición adicional 1. ${ }^{a}$ de la LOEPSF pergeña la creación de mecanismos adicionales de financiación a los que pueden acogerse tanto las CCAA como las CL $^{60}$ — estas direc-

59 Los resultados por CCAA, siguiendo el esquema (objetivo fijado/objetivo arrojado a final de año), son los siguientes: Andalucía (1,58 por 100/1,96 por 100), Aragón (1,30 por $100 / 1,47$ por 100$)$, Asturias (1,06 por $100 / 1,05$ por 100$)$, Baleares $(1,47$ por $100 / 1,30$ por 100$)$, Canarias ( 1,20 por $100 / 1,10$ por 100$)$, Cantabria (1,13 por $100 / 0,99$ por 100$)$, Castilla-La Mancha (1,30 por 100/2,04 por 100), Castilla y León (1,27 por 100/1,09 por 100), Cataluña (1,58 por $100 / 1,96$ por 100$)$, Extremadura (1,00 por $100 / 0,92$ por 100$)$, Galicia (1,20 por $100 / 1,10$ por 100$)$, La Rioja (1,06 por $100 / 1,04$ por 100$)$, Madrid (1,07 por $100 / 1,01$ por 100$)$, Murcia (1,59 por $100 / 2,30$ por 100$)$, Navarra $(1,20$ por $100 / 1,57$ por 100), País Vasco (1,20 por 100/1,08 por 100) y Valencia (1,06 por $100 / 2,60$ por 100).

${ }^{60}$ El Proyecto de Ley Orgánica de modificación de la LO 8/1980, de 22 de septiembre, de Financiación de las CCAA (LOFCA), y de la LO 2/2012, de 27 de abril, de Estabilidad Presupuestaria y Sostenibilidad Financiera (LOEPSF), ya reseñado en líneas precedentes, introduce importantes modificaciones en este sistema contenido en la DA $1 .{ }^{a}$ En apretada síntesis: introduce en el párrafo primero, en relación con el plan de ajuste que deben acordar el MHAP y las CCAA o CL que quieran acceder a la medida extraordinaria de financiación: «cuando el mismo sea preceptivo» (hasta el momento siempre lo era, por lo que no era necesaria diferenciación alguna); suprime en el párrafo segundo la referencia expresa a Ley $3 / 2004$, de 29 de diciembre, por la que se establecen medidas de lucha contra la morosidad en las operaciones comerciales, estableciendo en su lugar una fórmula más genérica y expansiva: «plazos legales de pago a proveedores establecidos en esta ley, la normativa sobre morosidad y en la normativa europea»; modifica el párrafo tercero, sustituyendo la referen- 
trices generales las desarrolla el Real Decreto-ley 21/2012, de 13 de julio, de Medidas de Liquidez de las Administraciones Públicas en el Ámbito Financiero-. Este Fondo de Liquidez Autonómica (FLA) nace con carácter extraordinario, temporal y voluntario, así como con la pretensión de amortiguar los efectos devastadores inherentes a una eventual situación de quiebra — en absoluto improbable - de determinadas regiones y municipios. Estos préstamos blandos han permitido que, desde su adopción, determinadas Administraciones - centraré este breve análisis en las CCAA - hayan podido obtener liquidez incluso en condiciones más beneficiosas que aquellas que no se han acogido a este sistema y que, por el contrario, han preferido incurrir en sobrecostes ${ }^{61}$, probablemente en la creencia de que su decisión resulta más rentable o beneficiosa a medio y largo plazo por la confianza que ello genera en su deuda de cara a los mercados internacionales. Este planteamiento, cuyas condiciones son aceptadas por unos y otros, se ve sustancialmente alterado en la reunión del CPFF de 23 de diciembre de 2014, en la que el Ministro de Hacienda propone nuevas medidas entre las que grosso modo destacan dos bien diferenciadas: 1) Una de aplicación a las CCAA que se han acogido al FLA desde su creación —Cataluña, Comunidad Valenciana, Andalucía, Asturias, Balea-

cia a la publicidad del plan de ajuste por: «el MHAP publicará información relativa al plan de ajuste», redacción más restrictiva que alberga ciertas dudas, puesto que una interpretación literal llevaría a concluir que asistimos a una retracción del estándar de transparencia impuesto inicialmente (el plan en su totalidad versus información relativa al mismo); altera la redacción del párrafo cuarto, letra $a$ ), quedando redactado de la siguiente manera: «avales públicos otorgados, riesgo vivo total acumulado por los mismos y operaciones o líneas de crédito contratadas identificando la entidad, total del crédito disponible y el crédito dispuesto»; en el párrafo quinto vuelve a introducir la alusión: «cuando el mismo sea preceptivo», en relación con el plan de ajuste, y, finalmente, introduce los párrafos octavo («si a partir de la aplicación de lo previsto en el art. 18.5 las corporaciones locales incluidas en el ámbito subjetivo definido en los arts. 111 y 135 del Texto Refundido de la Ley Reguladora de las Haciendas Locales persisten en el incumplimiento del plazo máximo de pago previsto en la normativa de morosidad, el Ministerio de Hacienda y Administraciones Públicas podrá determinar el acceso obligatorio de la corporación local a los mecanismos adicionales de financiación vigentes») y noveno («las operaciones de crédito que las Comunidades Autónomas concierten con cargo a los mecanismos adicionales de financiación cuyas condiciones financieras hayan sido previamente aprobadas por la Comisión Delegada del Gobierno para Asuntos Económicos quedarán exceptuadas de la autorización preceptiva del Estado y no les resultarán de aplicación las restricciones previstas en el apartado dos del art. 14 de la Ley Orgánica 8/1980, de 22 de septiembre, de Financiación de las Comunidades Autónomas, y en la disposición transitoria 3. a de esta ley»).

${ }^{61} \mathrm{La}$ aceptación de tales condiciones constituye una auténtica brida a su capacidad de gasto. Véase F. Escribano LóPEZ, «La autonomía financiera de las Comunidades Autónomas: crisis económica, estabilidad presupuestaria y sostenibilidad financiera», REDF, núm. 156 (2012), p. 26. 
res, Canarias, Cantabria, Murcia y Castilla-La Mancha-, a las que se perdonan los intereses devengados con efectos retroactivos a dicho momento. 2) Y otra de aplicación a las CCAA que no se han acogido al mismo, a las que ofrece financiación a interés cero con el fin de impedir que puedan endeudarse a tipos extremadamente altos —esta última recibe el nombre de Fondo de Facilidad Financiera (FFF), pues sus destinatarios son las Comunidades modelo o respetuosas con los objetivos de déficit, deuda y plazos de pago a proveedores-. Este giro inesperado no sólo genera una clara y notoria situación de desigualdad interregional, volviendo a favorecer a las entidades más díscolas, sino que además desvirtúa la propia naturaleza y virtualidad del FLA. Esta medida, tras la que se vislumbra un claro balo plurielectoralista —así como una falta de decisión para aplicar el aparato preventivo, correctivo y sancionador de la LOEPSF en todos sus términos o con la contundencia debida-, no sólo ignora la temporalidad de la medida, sino que, a través de la oferta de condiciones difícilmente mejorables en términos de mercado, fuerza su carácter facultativo intentando torcer la voluntad de las Administraciones reacias ab initio a acudir a la llamada rectora del Gobierno central.

Otro de los problemas reseñables que alberga esta normativa, tal vez el de mayor entidad, es el relativo a su enmarañada y compleja composición. No sólo por las abundantes remisiones - fundamentalmente a la normativa comunitaria—, sino también por la utilización sistemática de conceptos jurídicos indeterminados procedentes de la economía. Como afirma Violeta Ruiz Almendral: «Cabe preguntarse por los peligros de que el sistema descanse, de una manera tan fundamental, sobre estimaciones económicas, teniendo en cuenta la fungibilidad de las previsiones macroeconómicas, que si bien va ínsita en el término previsión tiende a interpretarse como casi una promesa, lo cual en parte viene propiciado por la propia configuración normativa del sistema de estabilidad presupuestaria» ${ }^{62}$. Y efectivamente debe interpretarse así, puesto que más allá de que las previsiones macroeconómicas sean variables y de que su extrapolación al ámbito jurídico resulte arriesgada — ambas premisas son ciertas—, si se apuesta por esta fusión sus efectos deben reconducirse necesariamente no ya al ámbito promisorio, sino al obligacional. Sin duda, que una norma descanse sobre presupuestos volátiles compromete su realización; en todo caso no estamos ante un problema nuevo, al menos en este campo.

${ }^{62}$ Véase V. Ruiz Almendral, «La nueva Ley de Estabilidad Presupuestaria y Sostenibilidad Financiera», Revista Española de Control Externo, vol. 14, núm. 41 (2012), pp. 109-110. 
La evolución numérica de los objetivos desde la aprobación de esta norma es rotundamente negativa:

1. En el año 2012, tras conceder la Comisión Europea la primera prórroga - anual - a nuestro país para cumplir las directrices del acervo comunitario, el objetivo de déficit se fija en el 6,30 por 100 del PIB (antes de dicha prórroga es del 5,30 por 100 del PIB). Se cierra el año con un déficit del 6,98 por 100 del PIB (si computamos las ayudas a la banca la cifra asciende al 10,30 por 100 del PIB).

2. En el año 2013, tras conceder la Comisión Europea la segunda prórroga - bianual - a nuestro país para cumplir las directrices ya referidas, el objetivo de déficit se fija en el 6,50 por 100 del PIB (antes de dicha prórroga es del 4,5 por 100 del PIB). Se cierra el año con un déficit del 6,80 por 100 del PIB (si computamos las ayudas a la banca la cifra asciende al 7,08 por 100 del PIB).

3. En el año 2014, el objetivo de déficit se fija en el 5,80 por 100 del PIB, aunque ante la mejora de las previsiones de crecimiento económico, en abril de ese año España decide reducirlo al 5,50 por 100 PIB. En el momento en que se escriben estas líneas todavía no son públicas las cifras definitivas, pero según las previsiones macroeconómicas de otoño de la Comisión, el porcentaje de cumplimiento orbitará alrededor del 5,60 por 100 del PIB.

Como se induce de la simple lectura de los datos aquí reflejados, España únicamente ha cumplido el objetivo de déficit correspondiente al año 2014, precedido de dos prórrogas y con matices (cumplimiento técnico o in extremis tras solicitar modificación a la baja motu proprio). Además, la Comisión Europea ya ha avanzado que es factible que también se incumplan ligeramente los objetivos previstos para el presente año 2015 (del 4,2 por 100 del PIB) ${ }^{63}$ y para 2016 (del 2,8 por 100 del PIB). La deuda pública no merece mucho comentario, pues es por todos conocido su crecimiento exponencial (en 2012 asciende al 84 por 100 del PIB, en 2013 al 94 por 100 del PIB y en 2014 al 98,10 por 100 del PIB. Según las previsiones del Gobierno español, en 2015 la cifra ascenderá hasta el

${ }^{63}$ Véanse el Informe sobre los proyectos y lineas fundamentales de los presupuestos de las Administraciones Públicas (Proyecto de Presupuestos Generales del Estado y líneas fundamentales de las Comunidades Autónomas y Corporaciones Locales 2015), publicado por la AIRF el 15 de octubre de 2014, y las Previsiones macroeconómicas de invierno de la Comisión Europea, presentadas el 5 de febrero de 2015. 
100,3 por 100 del PIB y en 2016 hasta el 101,5 por 100) que condiciona sobremanera el propósito de que la misma se sitúe en el 60 por 100 del PIB en $2020^{64}$.

Esta situación de incumplimiento reiterado y contrastado revela lo que desde la aprobación de la LOEPSF parece un secreto a voces a la luz de experiencias análogas vividas en el seno de la $\mathrm{UE}^{65}$ : la falta de firmeza política para aplicar con todas sus consecuencias el conglomerado de medidas preventivas, correctivas y coercitivas. Muestra de ello es la flexibilidad aplicativa y la desatención de los requerimientos internos (AIRF) y externos (Eurogrupo) en tal sentido.

Como colofón, no podemos obviar que la reciente STC 215/2014, de 18 de diciembre, que resuelve el recurso de inconstitucionalidad 557-2013 interpuesto por el gobierno de Canarias en relación con diversos preceptos de esta LOEPSF, avala íntegramente su contenido ${ }^{66}$. En todo caso, el sentir del Tribunal no es unánime, pues el pronunciamiento recoge un voto particular rubricado por cinco magistrados que evidencia — con buen criterio- la deficiente argumentación esgrimida para salvar el contenido de determinados preceptos de la norma. De esta sentencia se pueden extraer dos conclusiones, ambas preocupantes: 1) La misma, bebiendo de la fecunda jurisprudencia de 2011, reafirma y blinda la indiscutida facultad del Estado para verificar y controlar el gasto autonómico. Sin embargo va más allá, superando ciertos límites constitucionales hasta ahora insoslayables que resquebrajan el principio de autonomía — reducido a la mínima expresión-y realzan la posición preeminente del Estado ${ }^{67}$. 2) Corrobora la traslación del modelo comunitario al ámbito doméstico, desconociendo - como ya se ha apuntado en líneas precedentes- que estamos ante dos realidades político-territoriales plenamente diferenciadas. No cabe, por

${ }^{64}$ Véase la Opinión sobre el cumplimiento de los objetivos de déficit y deuda, publicada por la AIRF el 20 de julio de 2014.

${ }_{65}$ Recuérdese la Sentencia del Tribunal de Justicia de las Comunidades Europeas de 13 de julio de 2004 (asunto C 27/4, Comisión de las Comunidades Europeas vs. Consejo de la Unión Europea) y la posterior flexibilización de los contenidos del Pacto de Estabilidad y Crecimiento (PEC) en 2005, ante la falta de decisión para aplicar sus mandatos a Francia y Alemania.

${ }_{66}^{6}$ Queda pendiente de resolución el recurso de inconstitucionalidad 1762-2014 interpuesto contra determinados artículos de la LOCDCSP, cuya resolución afecta a la LOEPSF puesto que modifica determinadas previsiones contenidas en la misma, de lo que se ha dado buena cuenta.

${ }^{67}$ Véase Pleno, Sentencia 215/2014, de 18 de diciembre de 2014 (BOE, núm. 29, de 3 de febrero de 2015, pp. 145-146, voto particular, p. 2). 
tanto, transponer soluciones in abstracto y equiparar al gobierno nacional con la Comisión Europea ${ }^{68}$.

La normativa autonómica en materia de estabilidad presupuestaria presenta un alto grado de paralelismo con la sistemática y filosofía que impulsa la actividad del legislador estatal. Su contenido, aunque paupérrimo desde un punto de vista técnico, es respetuoso con la Constitución y la LOEPSF gracias a las últimas modificaciones introducidas. Modificaciones, dicho sea de paso, operadas a través de leyes de acompañamiento, que si bien cuentan con el refrendo del TC (STC 126/2011, de 13 de septiembre) no parecen un modelo prototípico de actuación, a pesar de su uso generalizado por las connotaciones de buida de control que redundan en su viabilidad. Existen, igualmente, dudas fundadas sobre la efectividad de este tipo de normas en el ámbito autonómico. Pudiera pensarse que aquellas CCAA que han aprobado legislación específica en la materia tienen un mayor grado de compromiso en la consecución y realización de los objetivos de estabilización de las cuentas públicas. Nada más lejos de la realidad. Si analizamos los datos comprobamos que de las cinco CCAA que disponen de normas ad hoc sobre estabilidad presupuestaria, tres incumplen sis-

${ }^{68}$ En relación a esta cuestión resulta de sumo interés la reflexión esgrimida por G. Orón Moratal en la conferencia pronunciada en la Universidad Complutense de Madrid el 10 de febrero de 2015 —organizada al auspicio del Instituto de Derecho Parlamentario y de los Proyectos de I+D+I Equidispres (DER 2012-37921-C02-01 y DER 2012037921-C02-02) bajo el título La constitucionalidad de la Ley de Estabilidad Presupuestariaen la que arguye lo siguiente: «El TC invoca en reiteradas ocasiones el principio iura novit curia en relación con la función jurisprudencial de los tribunales ordinarios, considerando que no se produce un exceso en la resolución de los mismos cuando acuden a normas distintas de las invocadas por los recurrentes en sus escritos. Siendo aplicable para estos tribunales ordinarios, en la medida en que el TC lleva a cabo una función jurisdiccional, entiendo que debe ser también aplicable al mismo; por tanto, la selección de la norma aplicable no entraña en modo alguno una incongruencia respecto de lo solicitado por las partes. Pues bien, en este caso ni el recurrente, ni el TC (mayoría), ni los magistrados disidentes hacen referencia a un precepto constitucional que, al menos, serviría para justificar la declaración de inconstitucionalidad de los art. 19, 25 y 26 LOEPSF. El Estado puede sin duda regular y exigir la responsabilidad en materia de estabilidad presupuestaria, pero quien debe controlar el cumplimiento no debe ser el MHAP, dejando al margen los supuestos excepcionales del art. 155 CE. Hasta llegar a esta solución residual, la LOEPSF prevé otras intervenciones por parte del Ministerio que suponen desconocer el art. $153 \mathrm{CE}$, precepto que atribuye expresamente y de forma exclusiva al TCu el control económico y presupuestario. Si la Constitución le atribuye esa competencia, cualquier forma de control que incida en la economía y en los presupuestos autonómicos debe necesariamente corresponder al mismo, con independencia de que ese control sea diferente a los contenidos en la Ley 47/2003, de 26 de noviembre, General Presupuestaria, o en la Ley Orgánica 2/1982, de 13 de mayo, del Tribunal de Cuentas. Ni siquiera por ley orgánica puede sustituirse a favor del gobierno la labor que constitucionalmente tiene atribuida el Tribunal Constitucional». 
temáticamente sus objetivos individuales —Cataluña, Aragón y Castilla-La Mancha-. Por el contrario, otras CCAA que carecen de normativa específica, pero que sí han ido adoptando medidas a través de diferentes disposiciones normativas, se ajustan a dichos objetivos y, en ocasiones, con cierta holgura.

\section{PERSPECTIVAS DE FUTURO}

Llegados a este punto, estamos en condiciones de afirmar que estas políticas tan rígidas tienen un alcance y efecto dudosos. Dos son los motivos que sustentan esta aseveración. El primero, la evolución de las grandes economías de la eurozona:

\begin{tabular}{|c|c|c|c|c|}
\hline Déficit & Alemania & Francia & Italia & España \\
\hline 1995 & -9.30 & -5.10 & -7.30 & -7.00 \\
\hline 1996 & -3.40 & -3.90 & -6.60 & -5.40 \\
\hline 1997 & -2.80 & -3.60 & -3.00 & -3.90 \\
\hline 1998 & -2.40 & -2.40 & -3.00 & -2.90 \\
\hline 1999 & -1.50 & -1.60 & -1.80 & -1.30 \\
\hline 2000 & $\mathbf{1 . 0 0}$ & -1.30 & -1.30 & -1.00 \\
\hline 2001 & -3.10 & -1.40 & -3.40 & -0.50 \\
\hline 2002 & -3.90 & -3.10 & -3.10 & -0.40 \\
\hline 2003 & -4.10 & -3.90 & -3.40 & -0.40 \\
\hline 2004 & -3.70 & -3.50 & -3.60 & $\mathbf{0 . 0 0}$ \\
\hline 2005 & -3.30 & -3.20 & -4.20 & $\mathbf{1 . 2 0}$ \\
\hline 2006 & -1.50 & -2.30 & -3.60 & $\mathbf{2 . 2 0}$ \\
\hline 2007 & $\mathbf{0 . 3 0}$ & -2.50 & -1.50 & $\mathbf{2 . 0 0}$ \\
\hline 2008 & $\mathbf{0 . 0 0}$ & -3.20 & -2.70 & -4.40 \\
\hline 2009 & -3.00 & -7.20 & -5.30 & -11.00 \\
\hline 2010 & -4.10 & -6.80 & -4.20 & -9.40 \\
\hline 2011 & -0.90 & -5.10 & -3.50 & -9.40 \\
\hline 2012 & $\mathbf{0 . 1 0}$ & -4.90 & -3.00 & $-10.30 *$ \\
\hline 2013 & $\mathbf{0 . 1 0}$ & -4.10 & -2.80 & -6.80 \\
\hline
\end{tabular}

Fuente: Elaboración propia (datos Eurostat).

* Se incluyen en esta cifra las ayudas a la banca.

A la hora de interpretar la evolución de estos porcentajes de déficit no podemos perder de vista que, con sus más y sus menos, la disciplina pre- 
supuestaria es algo connatural a la idea de UE, distinguiendo dos claros momentos de inflexión: el Tratado de Maastricht (1992) y el Tratado de Ámsterdam (1997) ${ }^{69}$. Durante el periodo 1995-2013 70 únicamente Alemania y España registran ejercicios superavitarios, el primero cinco (2000, 2007, 2008, 2012 y 2013) y el segundo cuatro (2004, 2005, 2006 y 2007). El contraste es desolador. De las cuatro primeras economías de la Eurozona, únicamente dos han conseguido que sus ingresos superaran a sus gastos en un periodo concreto en los últimos dieciocho años. Y salvando algunas excepciones, de manera exigua.

Si hablamos de deuda, observamos que en el tercer trimestre de 2014 la deuda pública de Alemania se sitúa en torno al 74,80 por 100 del PIB, la de Francia en el 95,30 por 100 del PIB, la de Italia en el 131,80 PIB y la de España en el 96,80 por 100 del PIB. Ninguna se ciñe al límite comunitario del 60 por 100 en relación con su PIB, por lo que, salvo Alemania - y con cierto esfuerzo, a pesar de su tendencia a la baja-, no parece factible que el resto de países puedan alcanzar dicha cifra a corto-medio plazo.

El segundo, los efectos secundarios y el fuerte impacto que tienen sobre grandes sectores poblacionales fruto de la afectación a las partidas presupuestarias destinadas a sufragar las políticas propias del Estado social.

En los últimos años, la estabilidad presupuestaria se viene asociando con la austeridad, a pesar de que aquélla representa un concepto mucho más amplio que en absoluto se identifica totalmente con ésta. Aunque pueda parecer obvio, la equiparación entre ambas se viene dando por hecho en no pocas ocasiones. Podría pensarse que el mimetismo entre estos conceptos es algo inocente, fruto de las circunstancias, o podría pensarse lo contrario. Lo cierto es que la debacle económico-financiera ha puesto sobre la mesa un debate que, al menos en nuestro país, era prácticamen-

${ }_{69}$ En el primero cristalizan los esfuerzos precedentes por articular verdaderamente la Unión Económica y Monetaria (UEM) —materializándose lo que en origen únicamente se fundamentaba en consideraciones teóricas - a través de la imposición de una serie de compromisos en materia de estabilidad macroeconómica tendentes a reducir el déficit público a partir de estrictas exigencias de coordinación y disciplina en la política fiscal. En el segundo se establecen una serie de compromisos tendentes a la unificación de conductas en materia fiscal, articulados con base en dos aspectos fundamentales: 1) la adopción de medidas presupuestarias necesarias para alcanzar los objetivos de sus programas de estabilidad, apostando por un salario público cercano o superior al equilibrio; 2) la adopción de medidas correctoras en caso de constatarse el riesgo de déficit excesivo, fundamentadas en la pertinente recomendación que al efecto formule la Comisión. Estas pretensiones se concretan a través del PEC.

${ }^{70}$ En el momento en que se cierra este artículo todavía no se han publicado los datos de 2014 . 
te inexistente. Me estoy refiriendo al control del gasto público. Llama la atención, sin embargo, que de forma paralela no se plantee el mismo debate en relación con los ingresos - o no con la contundencia debida, a tenor de las últimas reformas operadas en las normas que regulan las principales figuras impositivas de nuestro país, mal llamadas en su conjunto reforma fiscal- . Se habla de techo de gasto, pero se omite cualquier alusión al suelo de ingresos. Es aquí, precisamente, donde radica el principal escollo y donde, en adelante, debe incidirse. Sólo de esta manera podrá garantizarse la pervivencia del Estado social en un marco de estabilidad presupuestaria.

Las reformas estructurales son necesarias, comenzando por la de la propia Constitución. La preocupación por esta cuestión no es nueva ${ }^{71} \mathrm{y}$, en lo que aquí respecta, debe centrarse en tres aspectos:

1. $\quad$ Garantía de unos ingresos suficientes. La reforma del art. $135 \mathrm{CE}$ ha vuelto a copar — si alguna vez ha dejado de hacerlo- la actualidad política. En noviembre del pasado año se debate en el Congreso de los Diputados una propuesta promovida por Izquierda Plural que plantea la modificación del precepto con el fin de garantizar que se dé prioridad a los servicios públicos frente al pago de la deuda. La misma es rechazada con el voto en contra del Partido Popular, que goza de mayoría absoluta en la Cámara. Comparto dicha inquietud. Sin embargo, la cuestión es mucho más compleja y no parece hallar respuesta absoluta o unívoca en el ámbito interno ${ }^{72}$. Además, este planteamiento aporta una solución parcial al centrarse únicamente en la vertiente del gasto. Como afirma Diego López Garrido: «Si el déficit es imposible y el Estado del bienestar es uno de los principios constitucionales en España, hay que incluir en nuestra Constitución una fuerte cláusula de imposición progresiva directa que no discrimine en función del origen de la renta, como ahora sucede en perjuicio de las rentas del trabajo. Así, junto a la reforma del art. $135 \mathrm{CE}$ es necesaria otra, compensatoria del lado de los ingresos, que garantice la suficiencia o sostenibilidad de los ingresos tributarios y la pervivencia del modelo social» ${ }^{73}$.

${ }^{71}$ Tanto en el ámbito político — así se deprende del frustrado intento de enmienda constitucional planteado por el gobierno de José Luis Rodríguez Zapatero en su primera legislatura (2006) - como en el ámbito académico. Véase, entre otros, F. RuBio Llorente, «La necesidad de la reforma constitucional», en La reforma constitucional, Madrid, Ministerio de Justicia (2005), pp. 25-44.

72 Véase J. GonZÁlez GarCíA, «¿Podemos derogar el art. 135 CE?», El diario.es, publicado el 5 de abril de 2014.

73 Véase D. LóPEz GARRIDO, «Presentación», en VVAA, Reforma constitucional y estabilidad presupuestaria. El art. 135 de la Constitución, Madrid, Centro de Estudios Políticos y Constitucionales (2013), p. 15. 
2. $\quad$ Reforma del modelo territorial, Es necesario clarificar el reparto competencial para evitar disfunciones innecesarias. Existen varios informes de expertos elaborados en los últimos años y que pueden ser tomados en consideración a la hora de abordar una empresa de tal envergadura. Entre otros, el informe Propuestas para una reforma constitucional. Mejora de la calidad democrática y reforma del modelo territorial (pp. 19-21), elaborado en el año 2013 por varios profesores de Derecho constitucional de la Universidad de Zaragoza ${ }^{74}$, o Pautas para una reforma constitucional. Informe para el debate (pp. 99-115), elaborado a finales de 2014 por una veintena de profesores de diferentes universidades, disciplinas académicas, generaciones y sensibilidades políticas ${ }^{75}$.

3. Reforma del modelo de financiación autonómica. Como señala Juan Ignacio Gorospe Oviedo: «Habida cuenta que se partía de un Estado centralista, la financiación autonómica se ha caracterizado por su dependencia financiera del Estado mediante un sistema fundado inicialmente en la participación en los ingresos del Estado y unos impuestos cedidos de poca recaudación. Esta dependencia ha ido disminuyendo en relación directa con la progresiva responsabilidad en los ingresos -incrementando la recaudación y fijando competencias normativas de gestión en los impuestos cedidos- al tiempo que se cedían las competencias, pero no ha evitado un endeudamiento excesivo del que hoy en día adolecen las arcas autonómicas. En todo caso, el déficit y aumento de la deuda pública de las CCAA tiene también mucho que ver con una gestión inadecuada de los recursos públicos» ${ }^{76}$. La necesidad de reforma es palmaria. Me remito nuevamente a las recomendaciones enun-

${ }^{74}$ Este informe incluye un apartado relativo a la Constitucionalización de la lealtad institucional (pp. 37-43), en la línea con lo defendido en este artículo.

${ }^{75}$ A ésta debería suceder —y éste sería el orden lógico — una auténtica reforma de las Administraciones Públicas tomando en consideración las aportaciones de R. RIVERO ORTEGA, «Medidas para la sostenibilidad administrativa (austeridad, transparencia, eficiencia y racionalización). Análisis crítico de los arts. 32 y 36 de la Ley 2/2011, de 4 de marzo», Noticias de la Unión Europea, núm. 325 (2012), pp. 112-113: «La innovación es la solución de menor coste y mejor resultado; no basta con recortar gastos en los modelos existentes, es necesario inventar nuevos modelos. Y todo ello con base en la lógica de la llamada eficiencia radical, filosofía que pretende ahorrar costes en la prestación de los servicios sin rebajar la calidad de las prestaciones, todo ello mediante la innovación a través de la aplicación de nuevas aproximaciones, perspectivas y soluciones que parten de la posibilidad de contemplar nuevos puntos de vista, nuevos destinatarios de los servicios, nuevos proveedores o nuevos recursos. Creer en la colaboración y el acuerdo como la mejor estrategia para todos los actores de los procesos es fundamental».

76 Véase J. I. Gorospe Oviedo, «La estabilidad presupuestaria de las Comunidades Autónomas...», op. cit., p. 340. 
ciadas en los citados informes ${ }^{77}$, donde se plantean diferentes cuestiones todas ellas relevantes y de interés.

La preservación de la fiscalización del gasto en un marco de ingresos estable y suficiente, la racionalización orgánico-funcional y la redefinición de los recursos propios de los distintos niveles de Administración marcan el comienzo de una senda que ineludiblemente debemos seguir para romper nuestra vetusta tradición —al menos en lo jurídico- de empezar la casa por el tejado.

\section{BIBLIOGRAFÍA}

Álvarez Conde, E., «Presentación de la reforma (preventiva) constitucional de 2011», en VVAA, La constitucionalización de la estabilidad presupuestaria, Madrid, Instituto de Derecho Público-Universidad Rey Juan Carlos (2012), pp. 17-43.

Aragón Reyes, M., «La Ley Autonómica (a Luis Díez-Picazo y Ponce de León)», Revista Jurídica de la Universidad Autónoma de Madrid, núm. 6 (2002), pp. 23-39.

BAR CENDón, A., «La reforma constitucional y la gobernanza económica de la Unión Europea», Teoría y Realidad Constitucional, núm. 30 (2012), pp. 59-87.

Cayón Galiardo, A., «El principio de equilibrio presupuestario como límite al poder financiero de las Cortes Generales», en VVAA, Funciones financieras de las Cortes Generales, Madrid, Congreso de los Diputados (1985), pp. 83-152.

Contreras Casado, M., «Encuesta sobre la reforma de la Constitución», Teoría y Realidad Constitucional, núm. 29 (2012), pp. 11-76.

De la Hucha Celador, F., «La reforma del art. 135 de la Constitución: estabilidad presupuestaria y deuda pública», Revista Española de Derecho Financiero, núm. 153 (2012), pp. 21-48.

- «La deuda pública como recurso financiero en los distintos niveles de gobierno y sus limitaciones. El control del endeudamiento de las Administraciones Públicas», Crónica Presupuestaria, núm. 1 (2013), pp. 242-286.

Denia Cósimo, E., «En busca de la soberanía perdida. El principio de equilibrio presupuestario entre la coordinación constitucional y la reforma de la gobernanza económica de la Unión Europea», en VVAA, La constitucionalización de la estabilidad presupuestaria, Madrid, Instituto de Derecho Público-Universidad Rey Juan Carlos (2012), pp. 85-123.

77 Véase VVAA, Propuestas para una reforma constitucional. Mejora de la calidad democrática y reforma del modelo territorial, Zaragoza, Universidad de Zaragoza, 2013, pp. 21-37, y VVAA, Pautas para una reforma constitucional. Informe para el debate, Cizur Menor (Navarra), Aranzadi, 2014, pp. 115-125. 
Domínguez Martínez, J. M., y López Jiménez, J. M., «La reforma de la política de estabilidad presupuestaria en España: análisis de la Ley Orgánica de Estabilidad Presupuestaria y Sostenibilidad Financiera», Documentos de Trabajo (Instituto Universitario de Análisis Económico y Social de la Universidad de Alcalá), núm. 9 (2012).

Embid InUjo, A., La constitucionalización de la crisis económica, Madrid, Iustel (2012).

Alberti Robira, E., «La reforma del art. 135 CE», Revista Española de Derecho Constitucional, núm. 93 (2011), pp. 159-210.

Escribano LóPez, F., «La autonomía financiera de las Comunidades Autónomas: crisis económica, estabilidad presupuestaria y sostenibilidad financiera», Revista Española de Derecho Financiero, núm. 156 (2012), pp. 11-30.

EsParza Oroz, M., «El nuevo marco de la estabilidad presupuestaria en España», Revista Parlamentaria de la Asamblea de Madrid, núm. 26 (2012), pp. 153-202.

FAlCón y Tella, R., «La reforma del art. 135 de la Constitución», Revista General de Derecho Europeo, núm. 25 (2011).

FERnández Currás, M., «Principios rectores de la Ley Orgánica de Estabilidad Presupuestaria y Sostenibilidad Financiera», en VVAA, Estabilidad presupuestaria y sostenibilidad fiscal, Madrid, Instituto de Estudios Fiscales (2013), pp. 13-21.

Fernández Leiceaga, X., «La nueva normativa de estabilidad presupuestaria y sostenibilidad financiera y las Comunidades Autónomas», en VVAA, La consolidación fiscal en España: el papel de las Comunidades Autónomas y los municipios (experiencias, retos y perspectivas), Madrid, Instituto de Estudios Fiscales (2013).

Fernández Llera, R., «Colaboración público-privada como elusión de la estabilidad presupuestaria», Revista de Estudios Regionales, núm. extraordinario 86 (VIII) (2009), pp. 337-350.

Garcés SAnAgustín, M., «En torno al concepto de estabilidad presupuestaria en España», en VVAA, La estabilidad presupuestaria en el Derecho español, Madrid, Instituto de Estudios Fiscales (2004), pp. 19-44.

García-Escudero Márquez, P., «Sobre la reforma del art. 135 de la Constitución Española», Crónica Presupuestaria, núm. 1 (2013), pp. 94-105.

García-Moncó, A., «Déficit, deuda pública y soberanía financiera: la reforma del art. 135 de la Constitución», en VVAA, La constitucionalización de la estabilidad presupuestaria, Madrid, Instituto de Derecho Público-Universidad Rey Juan Carlos (2012), pp. 125-144.

García Pelayo, M., «Consideraciones sobre las cláusulas económicas de la Constitución», en Estudios sobre la Constitución Económica de 1978, Zaragoza, Universidad de Zaragoza (1979), pp. 27-53.

García Roca, J., y Martínez Lago, M. A., Estabilidad presupuestaria y consagración del freno al endeudamiento, Madrid, Aranzadi Thomson Reuters-Instituto de Derecho Parlamentario de la Universidad Complutense de Madrid (2013). 
GARCía ToRres, J., «El art. 155 de la Constitución española y el principio constitucional de autonomía», en Organización territorial del Estado, vol. II, Madrid, Instituto de Estudios Fiscales (1984), pp. 1189-1303.

Gónzalez García, J., «¿Podemos derogar el art. 135 CE?», El diario.es, publicado el 5 de abril de 2014.

Gorospe Oviedo, J. I., «La estabilidad presupuestaria de las Comunidades Autónomas y la reforma del art. 135 de la Constitución», en VVAA, La constitucionalización de la estabilidad presupuestaria, Madrid, Instituto de Derecho Público-Universidad Rey Juan Carlos (2012), pp. 339-372.

López Aguilar, J. F., «De la Constitución irreformable a la reforma constitucional exprés», Teoría y Realidad Constitucional, núm. 29 (2012), pp. 199-218.

López EsCudero, M., «Las interminables reformas de la gobernanza económica de la zona euro», Revista General de Derecho Europeo, núm. 27 (2012).

LÓPEZ GARRIDO, D., «Presentación», en VVAA, Reforma constitucional y estabilidad presupuestaria. El art. 135 de la Constitución, Madrid, Centro de Estudios Políticos y Constitucionales (2013).

Martínez Lago, M. A., «Crisis fiscal, estabilidad presupuestaria y reforma de la Constitución», El Cronista del Estado Social y Democrático de Derecho, núm. 24 (2011), pp. 10-21.

- «La reforma del régimen jurídico de la estabilidad presupuestaria y el Tratado de Estabilidad Coordinación y Gobernanza en la Unión Económica y Monetaria», Noticias de la Unión Europea, núm. 330 (2012), pp. 105-120.

— «La Ley Orgánica de Estabilidad Presupuestaria y Sostenibilidad Financiera: naturaleza, función y principios generales. Instrumentación de las reglas numéricas», Crónica Presupuestaria, núm. 1 (2013), pp. 147-185.

— «La Ley Orgánica de Estabilidad Presupuestaria y Sostenibilidad Financiera: estabilidad y supervisión de las reglas fiscales y corrección de los riesgos de incumplimiento», Crónica Presupuestaria, núm. 2 (2014), pp. 125-157.

NAvarro Fauré, A., «La aplicación de las medidas correctivas de control de la estabilidad presupuestaria y sostenibilidad financiera a las subvenciones», Revista Española de Derecho Financiero, núm. 164 (2014), pp. 61-77.

Orón Moratal, G., «El control del equilibrio presupuestario en los distintos niveles de gobierno», Crónica Presupuestaria, núm. 1 (2013), pp. 186-208.

- La constitucionalidad de la Ley de Estabilidad Presupuestaria, conferencia y debate sobre la sentencia del Tribunal Constitucional que avala la constitucionalidad de la LOEPSF y rechaza el recurso presentado por el gobierno de Canarias, pronunciada en la Facultad de Derecho de la UCM el 10 de febrero de 2015, organizada por el Instituto de Derecho Parlamentario y el Grupo de Investigación Equidispres.

Rivero Ortega, R., «Medidas para la sostenibilidad administrativa (austeridad, transparencia, eficiencia y racionalización). Análisis crítico de los arts. 32 y 
36 de la Ley 2/2011, de 4 de marzo», Noticias de la Unión Europea, núm. 325 (2012), pp. 111-118.

Rodríguez Bereijo, A., «La reforma constitucional del art. 135 y la crisis financiera del Estado», Crónica Presupuestaria, núm. 1 (2013), pp. 5-39.

— «La reforma constitucional del art. 135 y la crisis financiera del Estado», Otrosí. Revista del Ilustre Colegio de Abogados de Madrid, núm. 11 (2012), pp. 11 y ss.

Rubio Llorente, F., «La necesidad de la reforma constitucional», en La reforma constitucional, Madrid, Ministerio de Justicia (2005), pp. 25-44.

Ruiz AlmENDRAL, V., «Estabilidad presupuestaria y reforma constitucional», Revista Española de Derecho Europeo, núm. 41 (2012), pp. 33-110.

- «La nueva Ley de Estabilidad Presupuestaria y Sostenibilidad Financiera», Revista Española de Control Externo, vol. 14, núm. 41 (2012), pp. 97-122.

Sesma SÁnCHEZ, B., «El principio de transparencia presupuestaria», Crónica Presupuestaria, núm. 1 (2013), pp. 209-241.

Soriano García, J. E., Derecho público de la competencia, Madrid, Marcial Pons (1998).

Tajadura Tejada, J., «Reforma constitucional e integración europea», Claves de Razón Práctica, núm. 216 (2011), pp. 20-28.

VVAA, Pautas para una reforma constitucional. Informe para el debate, Cizur Menor (Navarra), Aranzadi (2014).

VVAA, Propuestas para una reforma constitucional. Mejora de la calidad democrática y reforma del modelo territorial, Zaragoza, Universidad de Zaragoza (2013). 
